\title{
Molecular characterization of Legionella pneumophila-induced interleukin-8 expression in T cells
}

\author{
Reika Takamatsu', Hiromitsu Teruya ${ }^{1,2}$, Eriko Takeshima ${ }^{1,2}$, Chie Ishikawa ${ }^{1,3}$, Kunihiro Matsumoto $^{4}$, \\ Naofumi Mukaida ${ }^{5}$, Jian-Dong Li $i^{6}$, Klaus Heuner ${ }^{7}$, Futoshi Higa ${ }^{2}$, Jiro Fujita ${ }^{2}$, Naoki Mori ${ }^{* *}$
}

\begin{abstract}
Background: Legionella pneumophila is the causative agent of human Legionnaire's disease. During infection, the bacterium invades macrophages and lung epithelial cells, and replicates intracellularly. However, little is known about its interaction with $T$ cells. We investigated the ability of $L$. pneumophila to infect and stimulate the production of interleukin-8 (IL-8) in T cells. The objective of this study was to assess whether L. pneumophila interferes with the immune system by interacting and infecting $T$ cells.

Results: Wild-type L. pneumophila and flagellin-deficient Legionella, but not $L$. pneumophila lacking a functional type IV secretion system Dot/lcm, replicated in T cells. On the other hand, wild-type L. pneumophila and Dot/lcm-deficient Legionella, but not flagellin-deficient Legionella or heat-killed Legionella induced IL-8 expression. L. pneumophila activated an IL-8 promoter through the NF- $\kappa \mathrm{B}$ and AP-1 binding regions. Wild-type L. pneumophila but not flagellin-deficient Legionella activated NF- $\kappa$ B, p38 mitogen-activated protein kinase (MAPK), Jun N-terminal kinase (JNK), and transforming growth factor $\beta$-associated kinase 1 (TAK1). Transfection of dominant negative mutants of $|\kappa B \alpha,| \kappa B$ kinase, NF- $\kappa$ B-inducing kinase, TAK1, MyD88, and p38 MAPK inhibited L. pneumophila-induced IL-8 activation. Inhibitors of NF- $\kappa$ B, p38 MAPK, and JNK blocked L. pneumophila-induced IL-8 expression. In addition, c-Jun, JunD, cyclic AMP response element binding protein, and activating transcription factor 1 , which are substrates of p38 MAPK and JNK, bound to the AP-1 site of the IL-8 promoter.

Conclusions: Taken together, L. pneumophila induced a flagellin-dependent activation of TAK1, P38 MAPK, and JNK, as well as NF- $\kappa$ B and AP-1, which resulted in IL-8 production in human T cells, presumably contributing to the immune response in Legionnaire's disease.
\end{abstract}

\section{Background}

The gram-negative bacteria Legionella pneumophila is the causative pathogen of Legionnaires' disease, a potentially fatal type of pneumonia affecting both immunocompromised and immunocompetent subjects. This bacterium is a facultative intracellular pathogen of amoeba in natural and man-made aquatic environments. Infection of humans occurs after inhalation of contaminated water aerosol droplets. Dependent on its type IV secretion system Dot/Icm, L. pneumophila initiates biogenesis of a specialized vacuole that it critical for Legionella replication [1]. This

\footnotetext{
* Correspondence: n-mori@med.u-ryukyu.ac.jp

'Division of Molecular Virology and Oncology, Graduate School of Medicine, University of the Ryukyus, 207 Uehara, Nishihara, Okinawa 903-0215, Japan
}

Legionella-containing vacuole avoids fusion with lysosomes and acquires vesicles from the endoplasmic reticulum [2]. In addition, the bacterial flagellum with its major component flagellin is also considered to represent a virulence-associated factor [3].

For L. pneumophila pathogenesis, important results were obtained by analyzing infection of protozoans or immune cells like macrophages [4]. However, recent studies have shown that L. pneumophila replicates also in human alveolar epithelial cells [5,6]. Although Legionella less efficiently replicates within human $\mathrm{T}$ cells compared with macrophages [7], little is known of the consequences of $\mathrm{T}$ cell infection with Legionella.

The objective of this study was to assess whether L. pneumophila interferes with the immune system by 
interacting and infecting $\mathrm{T}$ cells. The results demonstrated that $L$. pneumophila interacted with and infected $\mathrm{T}$ cells. To investigate $L$. pneumophila-T cell interactions, we examined whether $L$. pneumophila induces production of interleukin-8 (IL-8), an inflammatory chemokine associated with immune-mediated pathology and involved in recruitment and activation of neutrophils and other immune cells. The results showed that L. pneumophila directly increased IL-8 by activation of transforming growth factor $\beta$-associated kinase 1 (TAK1), p38 mitogen-activated protein kinase (MAPK), and Jun N-terminal kinase (JNK), leading to activation of transcription factors, NF- $\kappa \mathrm{B}, \mathrm{AP}-1$, cyclic AMP response element (CRE) binding protein (CREB), and activating transcription factor-1 (ATF1).

\section{Results}

Multiplication of $L$. pneumophila in human T cells

To investigate the interaction of L. pneumophila with $\mathrm{T}$ cells, we first examined intracellular growth of
L. pneumophila strain AA100jm in Jurkat cells by $72-\mathrm{h}$ continuous cultures. The CFU per well of AA100jm growing in Jurkat cell cultures began to increase after 24 $\mathrm{h}$ and then increased time-dependently (Fig. 1A). However, the CFU of the avirulent mutant strain with a knockout in $\operatorname{dot} O$, encoding a protein essential for type IV secretion system, did not increase during the 72-h period (Fig. 1A). In contrast, the multiplication of fla $\mathrm{A}$ mutant did not change in Jurkat cells compared with the wild-type Corby (Fig. 1B). To characterize the multiplication of L. pneumophila in human T cells, intracellular growth in $\mathrm{CD} 4^{+} \mathrm{T}$ cells of $L$. pneumophila was examined. The CFU of the wild-type Corby increased after infection for $24 \mathrm{~h}$ in $\mathrm{CD}^{+} \mathrm{T}$ cells, although it replicated less efficiently compared with the observations with Jurkat cells (Fig. 1C). Staining of the infected Jurkat cells for L. pneumophila showed increased intracellular replication of AA100jm, Corby, and flaA mutant, but not $\operatorname{dot} O$ mutant after $24 \mathrm{~h}$ in culture (Fig. 1D and 1E). These observations suggest that $L$. pneumophila can replicate in human

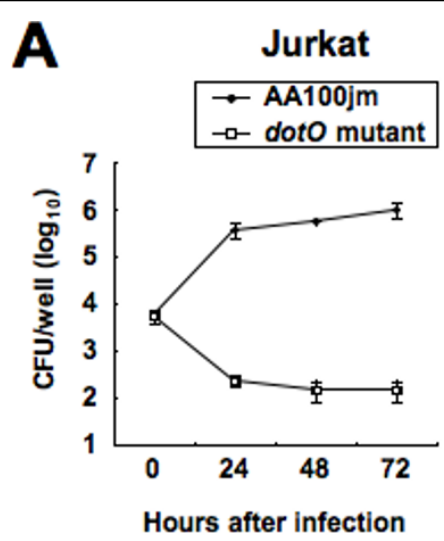

D

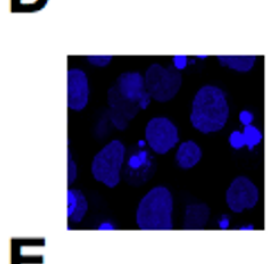

E
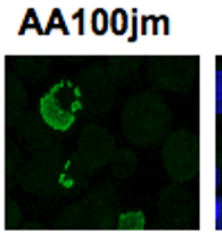

Corby
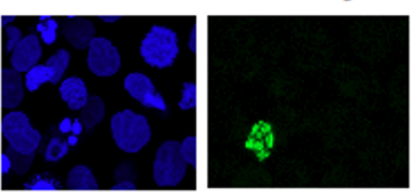

DAPI L. pneumophila

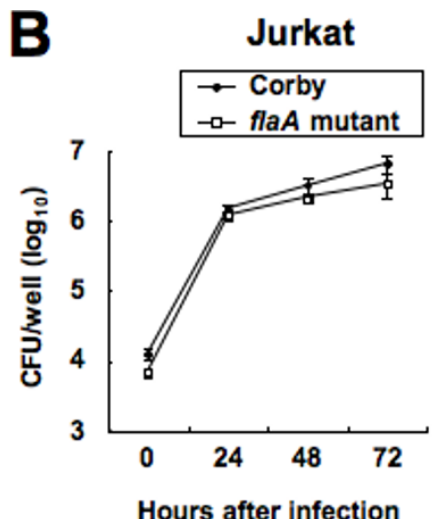

Hours after infection

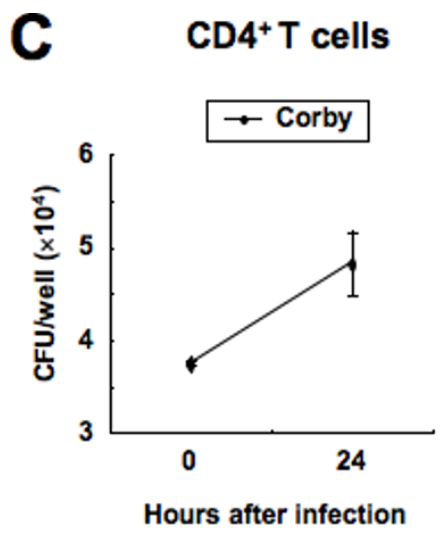

dotO mutant
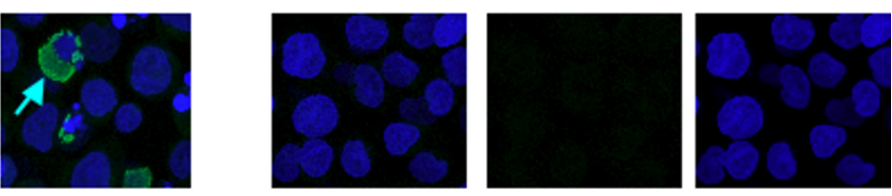

flaA mutant
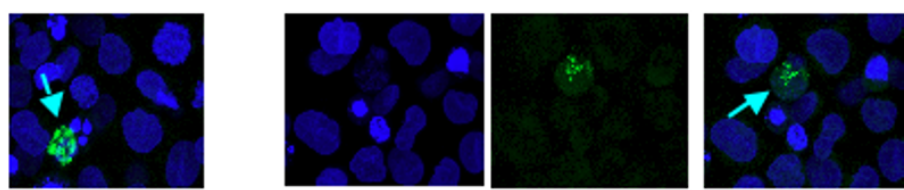

DAPI L. pneumophila Merge

Figure 1 Intracellular growth of L. pneumophila strains in Jurkat cells and CD4 ${ }^{+} \mathbf{T}$ cells. Jurkat cells were infected with $L$. pneumophila strains AA100jm and dotO mutant ( $\mathrm{MOI}$ of 100) (A) or Corby and flaA mutant (MOI of 100) (B). (C) CD4 ${ }^{+}$T cells were also infected with Corby (MOI of 50). At the indicated time points after infection, the CFU was enumerated. Data are mean \pm SD of triplicate cell cultures. (D and E) Direct fluorescent antibody staining of L. pneumophila strains. Jurkat cells were infected with AA100jm and dotO mutant (MOI of 100) (D) or Corby and flaA mutant (MOI of 100) (E) for $24 \mathrm{~h}$. Jurkat cells were stained with fluorescein-conjugated anti-L. pneumophila antibody. Original magnification, $\times 600$. 
T cells and the type IV secretion system plays a role in $L$. pneumophila replication in human T cells.

High serum IL-8 levels in patients with Legionella pneumonia

To investigate the role of IL- 8 in the pathogenesis of Legionella pneumonia, the circulating concentrations of IL-8 were measured. Serum IL-8 levels were higher in patients with Legionella pneumonia $(n=18)(189 \pm 493$ $\mathrm{pg} / \mathrm{ml})$ than in normal healthy controls $(n=16)(9.79 \pm$ $15.06 \mathrm{pg} / \mathrm{ml}$ ), although this difference was not statistically significant $(P=0.157)$. Therefore, we analyzed the signaling pathways for IL-8 activation by Legionalla infection.

Infection of Jurkat and $\mathrm{CD}^{+}{ }^{+}$cells by L. pneumophila induces IL-8 expression

Jurkat cells were infected with wild-type L. pneumophila strains AA100jm and Corby for up to $12 \mathrm{~h}$. Total cellular RNA was isolated from these cells at 0.5, 1, 2, 4, 6, 8 and $12 \mathrm{~h}$ after the infection and IL-8 gene expression was analyzed by RT-PCR. IL-8 mRNA expression increased after the infection (Fig. 2A). In another series of experiments, in which Jurkat cells were infected with AA100jm and
Corby at different concentrations for $4 \mathrm{~h}$ (Fig. 2B), both strains induced dose-dependent expression of IL-8 mRNA. Next, we examined the correlation between IL-8 expression levels and the virulence of $L$. pneumophila. As shown in Fig. 2A, IL-8 mRNA expression was induced after infection with the avirulent $\operatorname{dot} O$ mutant, but became gradually weaker from 8 to $12 \mathrm{~h}$. In contrast, a flaA knockout mutant, defective in flagellin production, failed to induce IL-8 mRNA after infection (Fig. 2A). To characterize the effect of $L$. pneumophila infection on human T cells, IL-8 mRNA expression in $\mathrm{CD} 4^{+} \mathrm{T}$ cells in response to L. pneumophila was examined by RT-PCR. After infection for $3 \mathrm{~h}, \mathrm{~L}$. pneumophila induced IL-8 mRNA expression in $\mathrm{CD}^{+} \mathrm{T}$ cells, similar to the observations with Jurkat cells (Fig. 2C).

To determine the correlation between IL-8 expression level and L. pneumophila bacterial proteins, heat-killed Corby was used to infect Jurkat cells at a multiplicity of infection (MOI) of 100. At $4 \mathrm{~h}, \mathrm{IL}-8$ was not expressed in Jurkat cells infected with the heat-killed strain (Fig. 2D). Furthermore, IL-8 gene expression was not induced when paraformaldehyde-fixed $L$. pneumophila
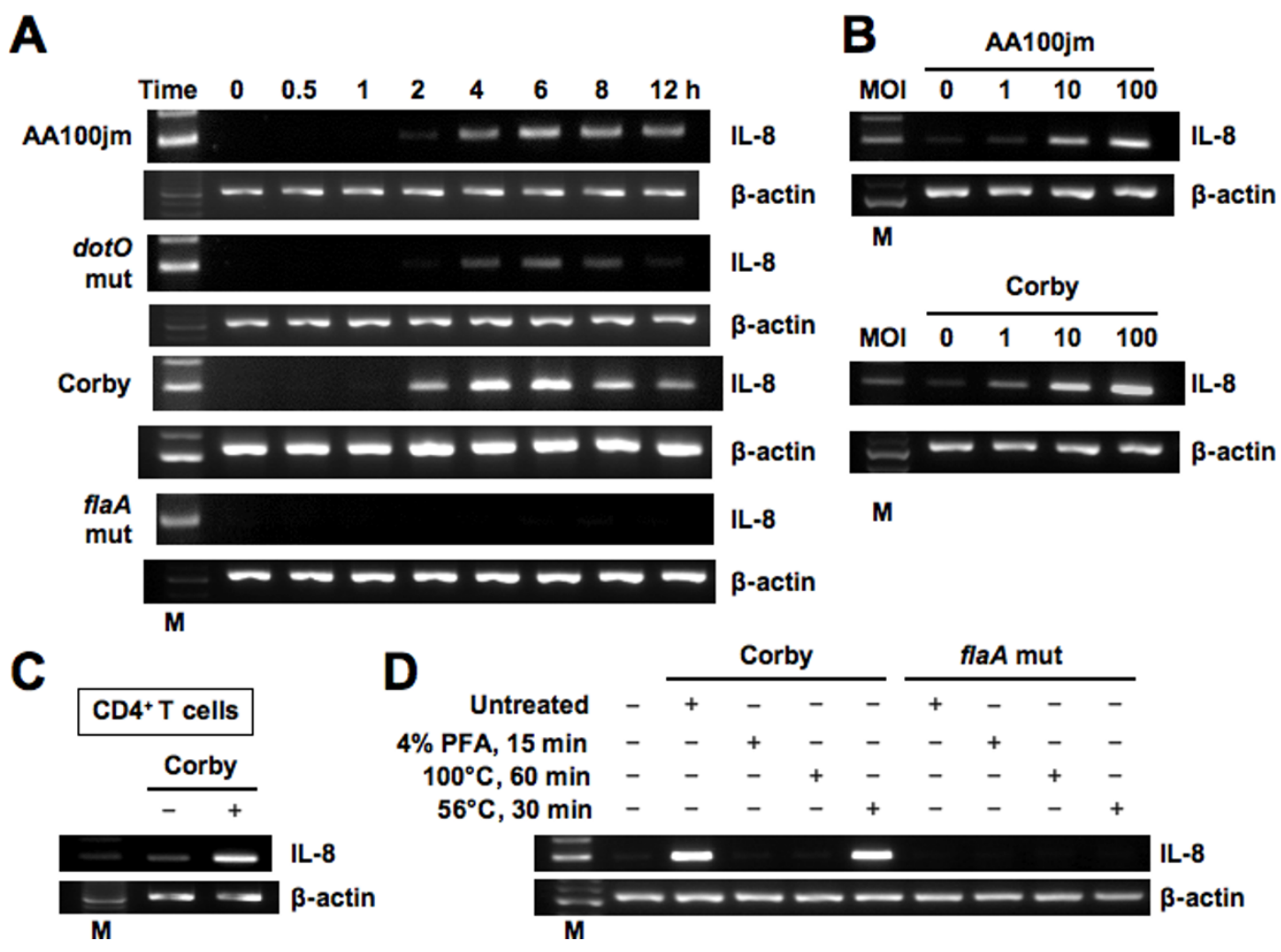

M

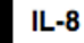

\section{$\beta$-actin}

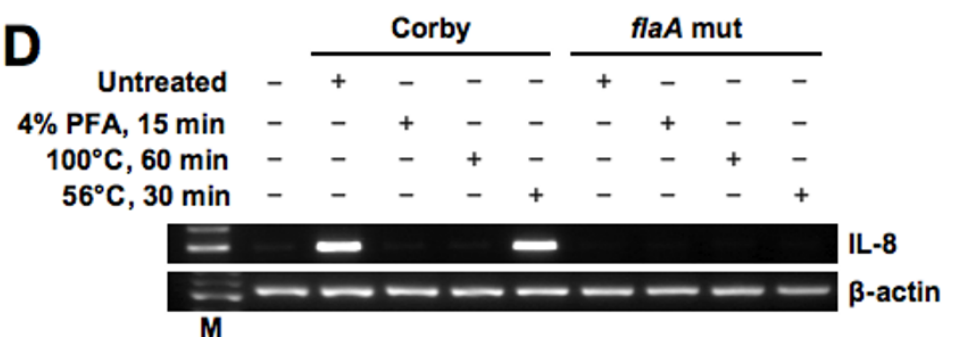

Figure 2 L. pneumophila-induced IL-8 mRNA expression in T cells. (A) Total RNA was extracted from Jurkat cells infected with AA100jm dotO mutant, Corby, or flaA mutant (MOI of 100) for the indicated time intervals and used for RT-PCR. (B) Jurkat cells were infected with the indicated concentrations of L. pneumophila for $4 \mathrm{~h}$. Total RNA was extracted and used for RT-PCR. (C) Total RNA was extracted from CD4 ${ }^{+} \mathrm{T}$ cells infected with Corby (MOI of 50) for $3 \mathrm{~h}$ and used for RT-PCR. (D) Jurkat cells were infected with live L. pneumophila Corby or flaA mutant (MOI of 100) for $4 \mathrm{~h}$ or incubated with L. pneumophila under the indicated treatment for $4 \mathrm{~h}$. PFA, paraformaldehyde. Total RNA was extracted and used for RT-PCR. Representative examples of three experiments with similar results. 
was used (Fig. 2D). However, bacteria heated at $56^{\circ} \mathrm{C}$ for 30 min induced IL-8 expression. These results suggest that the surface proteins of bacteria but not lipopolysaccharide are required for IL-8 induction. Considered together, it seems that Legionella flagellin is involved in IL-8 expression in T cells.

Flagellin is recognized by toll-like receptor 5 (TLR5) [8]. Thus, we also examined the expression of TLR2, TLR3, TLR4, and TLR5 mRNAs in Jurkat and CD4 ${ }^{+} \mathrm{T}$ cells. All TLR mRNAs examined were expressed in Jurkat and $\mathrm{CD}^{+} \mathrm{T}$ cells (Fig. 3A and 3B). Furthermore, their expression levels did not change by L. pneumophila infection in $\mathrm{CD}^{+} \mathrm{T}$ cells (Fig. 3B) and Jurkat cells (data not shown).

IL-8 production from Jurkat cells during infection with L. pneumophila

We used enzyme-linked immunosorbent assay (ELISA) to determine IL- 8 protein levels in culture supernatants of Jurkat cells at 8,12 , or $24 \mathrm{~h}$ after infection with either the parental strain Corby or flaA mutant strain at an MOI of 100 . IL- 8 was induced by Corby in a timedependent manner. On the other hand, the amount of IL- 8 produced by Jurkat cells infected with the flaA mutant strain was significantly less than that by cells infected with the wild-type strain (Fig. 4A). Corbyinduced IL- 8 production by Jurkat cells was MOIdependent (Fig. 4B). Corby also induced a significant amount of IL-8 from CD4 ${ }^{+} \mathrm{T}$ cells (Fig. 4C).

L. pneumophila induces IL-8 gene transcription via a sequence spanning positions -133 to -50 of the IL-8 gene promoter

To delineate the mechanism by which L. pneumophila induces IL-8 gene transcription, we identified L. pneumophila-responsive promoter elements in the IL-8 promoter. This was achieved by transfecting Jurkat cells with various plasmid constructs containing the luciferase reporter gene driven by the IL- 8 promoter. Twenty-four hours post-transfection, cells were infected with $L$. pneumophila strain Corby. L. pneumophila infection resulted in activation of the 5 ' region $1,481 \mathrm{bp}$ full-length promoter in an MOI-dependent manner (Fig. 5A). These results indicate that L. pneumophila induces IL-8 expression in Jurkat cells at transcriptional level. Next, we used a deletion analysis approach to identify the essential promoter element(s) for transcriptional upregulation following a stimulus. High induction levels were observed with a reporter construct containing IL-8 5'-flanking sequence starting with position $-1,481$ to position -133 . Deletion of sequences upstream of position -50 abolished induction of IL-8 by L. pneumophila infection (Fig. 5B). The IL-8 gene fragment spanning positions -133 to -50 bp contains three prominent DNA-protein interaction sites for the transcription factors AP-1, nuclear factor IL-6 (NF-IL-6), and NF- $\kappa \mathrm{B}$ (Fig. $5 \mathrm{~B}$ ). This maps the region from -133 to $-50 \mathrm{bp}$ as a $L$. pneumophila-responsive region, which is likely to contain individual L. pneumophila-responsive regulatory elements.

To identify the cis-acting element(s) in the -133 to $-50 \mathrm{bp}$ region of the IL- 8 promoter, which served as a L. pneumophila-responsive regulatory element, we prepared and tested site-directed mutant constructs (Fig. 5C). Mutation in the NF- $\kappa \mathrm{B}$ site (NF- $\kappa \mathrm{B}$ mut-luc) and AP-1 site (AP-1 mut-luc) suppressed L. pneumophila-induced IL-8 expression. However, mutation of the NF-IL-6 site (NF-IL-6 mut-luc) had no such effect. These results indicate that activation of the IL-8 promoter in Jurkat cells in response to $L$. pneumophila infection requires an intact binding site for the NF- $\kappa$ B and AP-1 elements.

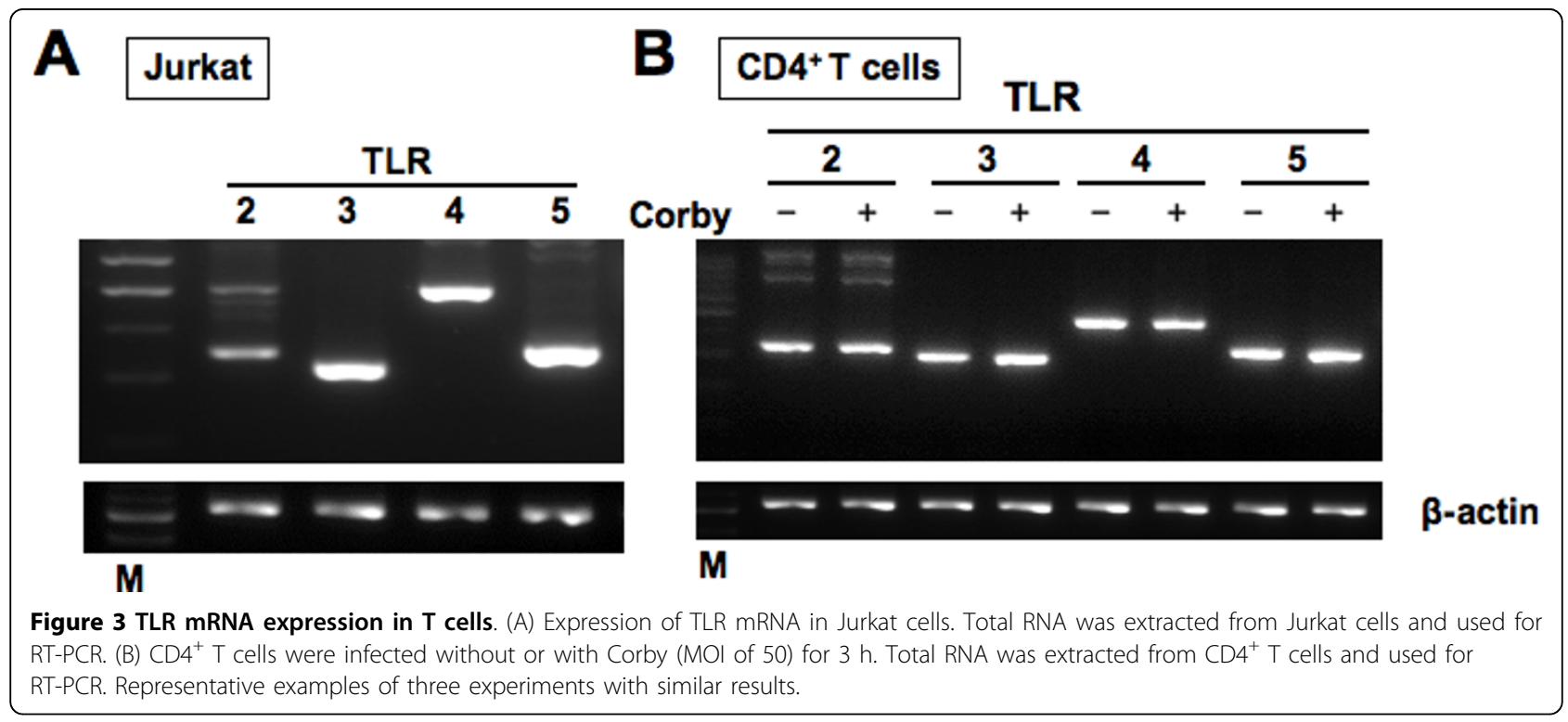




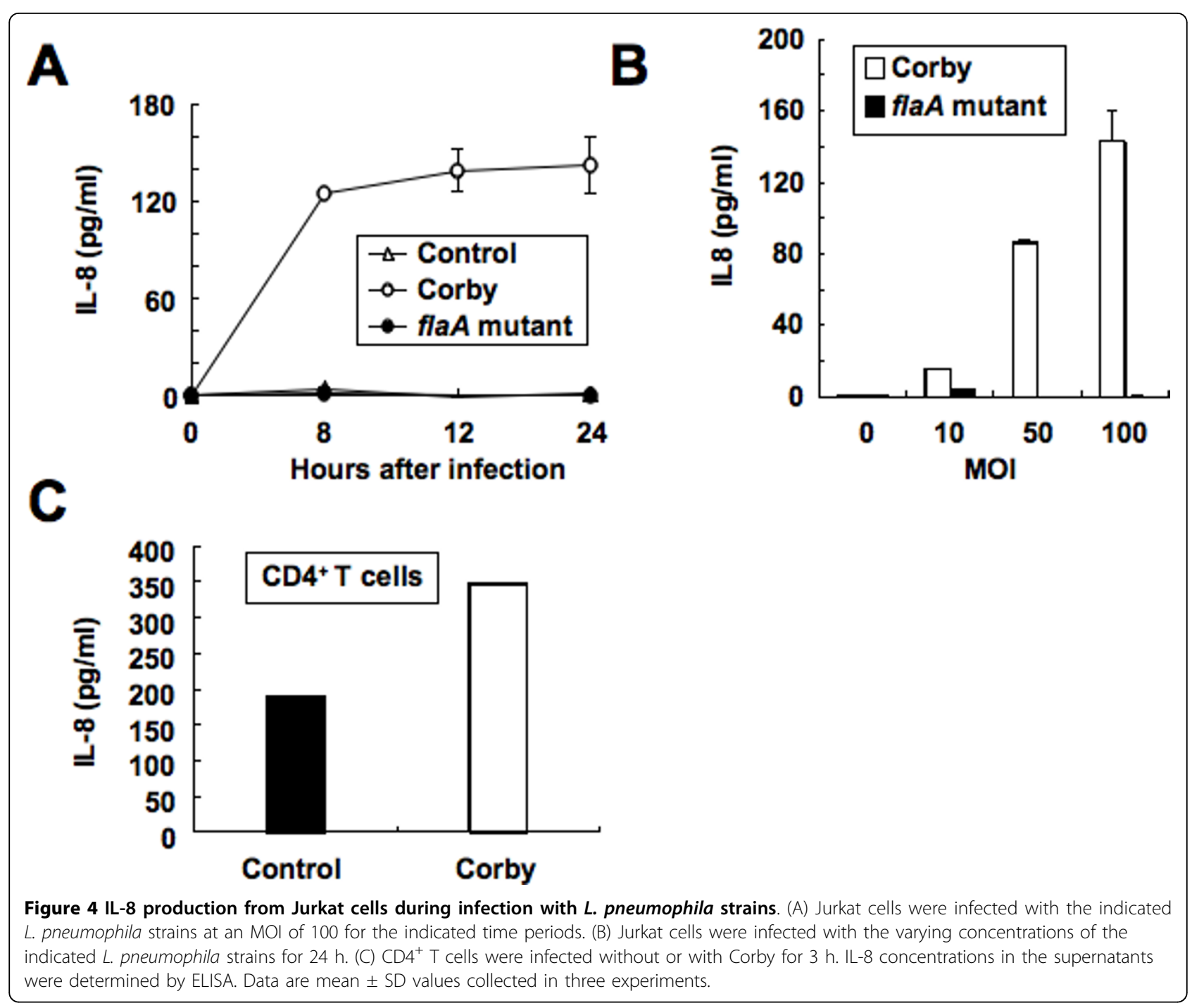

Flagellin-dependent activation of NF- $\kappa \mathrm{B}$

Because the internal mutational analysis of IL-8 promoter indicated that L. pneumophila infection activated transcription through the NF- $\kappa \mathrm{B}$ site, it was important to identify the nuclear factor(s) that binds to this site. The NF- $\kappa \mathrm{B}$ sequence derived from the IL- 8 promoter was used as a probe in electrophoretic mobility shift assay (EMSA). Jurkat cells were infected with Corby strain at different times after challenge, and nuclear protein extracts were prepared and analyzed to determine NF- $\kappa$ B DNA binding activity. As shown in Fig. 6A, a complex was induced in these cells within $30 \mathrm{~min}$ after infection with Corby and increased in a time-dependent manner. This NF- $\kappa$ B binding activity to IL- 8 promoter was reduced by the addition of either cold probe or a typical NF- $\kappa \mathrm{B}$ sequence derived from the IL-2 receptor (IL-2R) $\alpha$-chain (IL-2R $\alpha$ ) enhancer but not by an oligonucleotide containing the AP-1 binding site (Fig. 6B, lanes 3 to 5). Next, we characterized the L. pneumophila-induced complexes identified by the IL- 8 NF- $\kappa \mathrm{B}$ probe. These complexes were diminished and supershifted by the addition of anti-p50 or anti-p65 antibody (Fig. 6A, lanes 6 to 10), suggesting that L. pneumophilainduced IL-8 NF- $\kappa$ B complexes are composed of p50 and p65. Based on these results, one can conclude that L. pneumophila infection seems to induce IL- 8 gene expression at least in part through induced binding of p50 and p65 to the NF- $\kappa$ B site in the IL- 8 promoter region.

As described above, the flaA mutant strain failed to induce mRNA expression and production of IL-8. Next, we determined whether the flaA mutant strain induces NF- $\kappa$ B DNA binding activity. As expected, NF- $\kappa$ B DNA binding activity was not induced by the isogenic flaA mutant, unlike the wild-type strain Corby (Fig. 6A). These results indicate that better activation of NF- $\kappa \mathrm{B}$ 


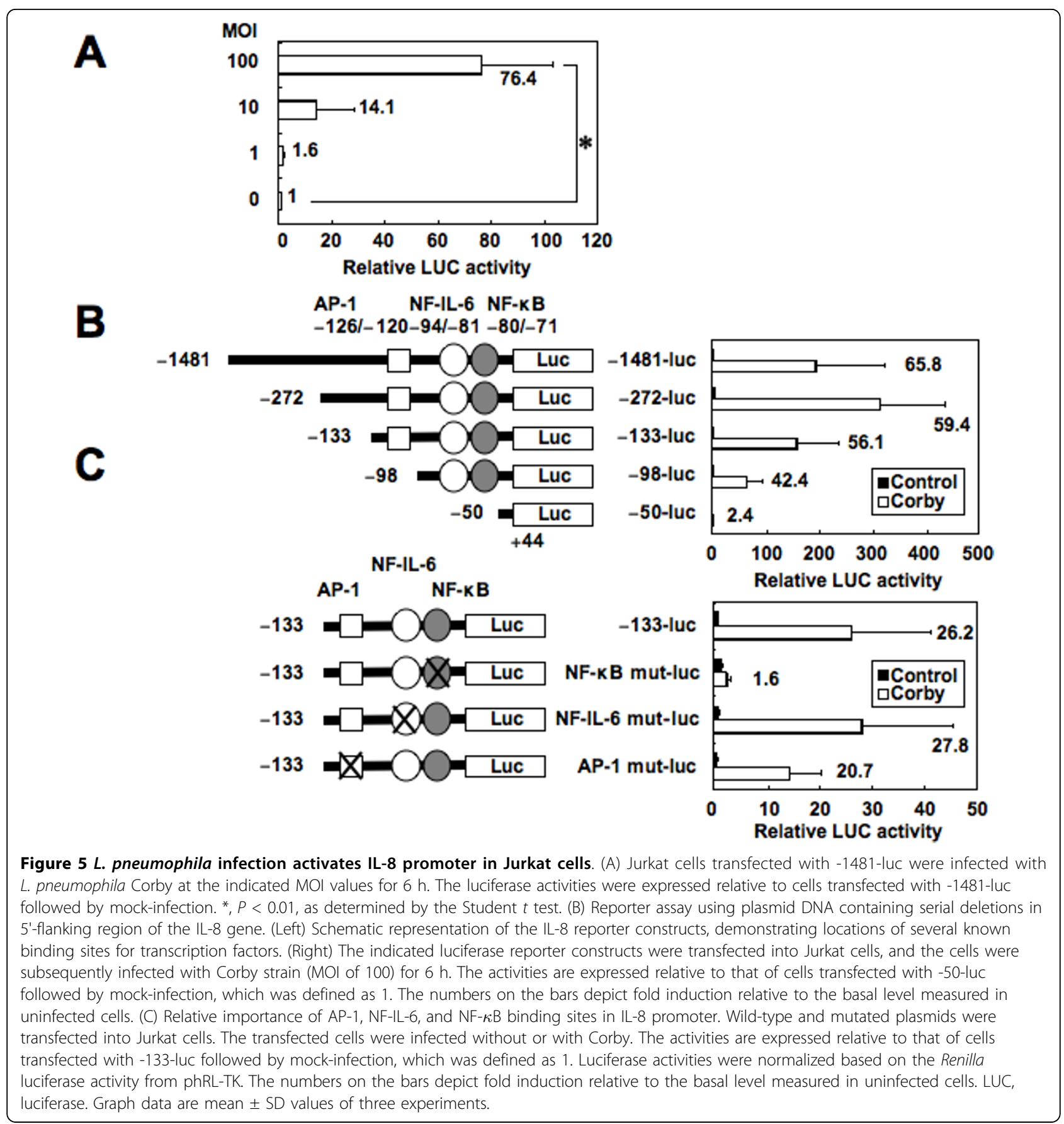

binding by flaA-positive strain is the underlying mechanism of the observed activation of the IL- 8 promoter by this bacterial strain. Considered together, these results indicate that $L$. pneumophila infection induces IL-8 gene expression at least in part through the induced binding of p50 and p65 NF- $\kappa \mathrm{B}$ family members to the NF- $\kappa \mathrm{B}$ element of the IL- 8 promoter and that this effect is dependent on flagellin.

Because nuclear translocation is a key step for transcriptional activity [9], we next examined whether
L. pneumophila induces the nuclear translocation of NF- $\kappa$ B. As shown in Fig. $6 \mathrm{C}$, the wild-type Corby, but not the flaA mutant, induced nuclear translocation of $\mathrm{NF}-\kappa \mathrm{B}$. NF- $\kappa \mathrm{B}$ is normally present in the cytoplasm in an inactive state and is bound to members of the $\mathrm{I} \kappa \mathrm{B}$ inhibitor protein family, chiefly $\mathrm{I} \kappa \mathrm{B} \alpha$. In this complex, $\mathrm{I} \kappa \mathrm{B} \alpha$ blocks the nuclear localization signal, thus preventing nuclear translocation. Translocation of NF- $\kappa \mathrm{B}$ into the nucleus requires disruption of the cytoplasmic NF- $\kappa \mathrm{B}: \mathrm{I} \kappa \mathrm{B} \alpha$ complex [9]. To determine the role of 


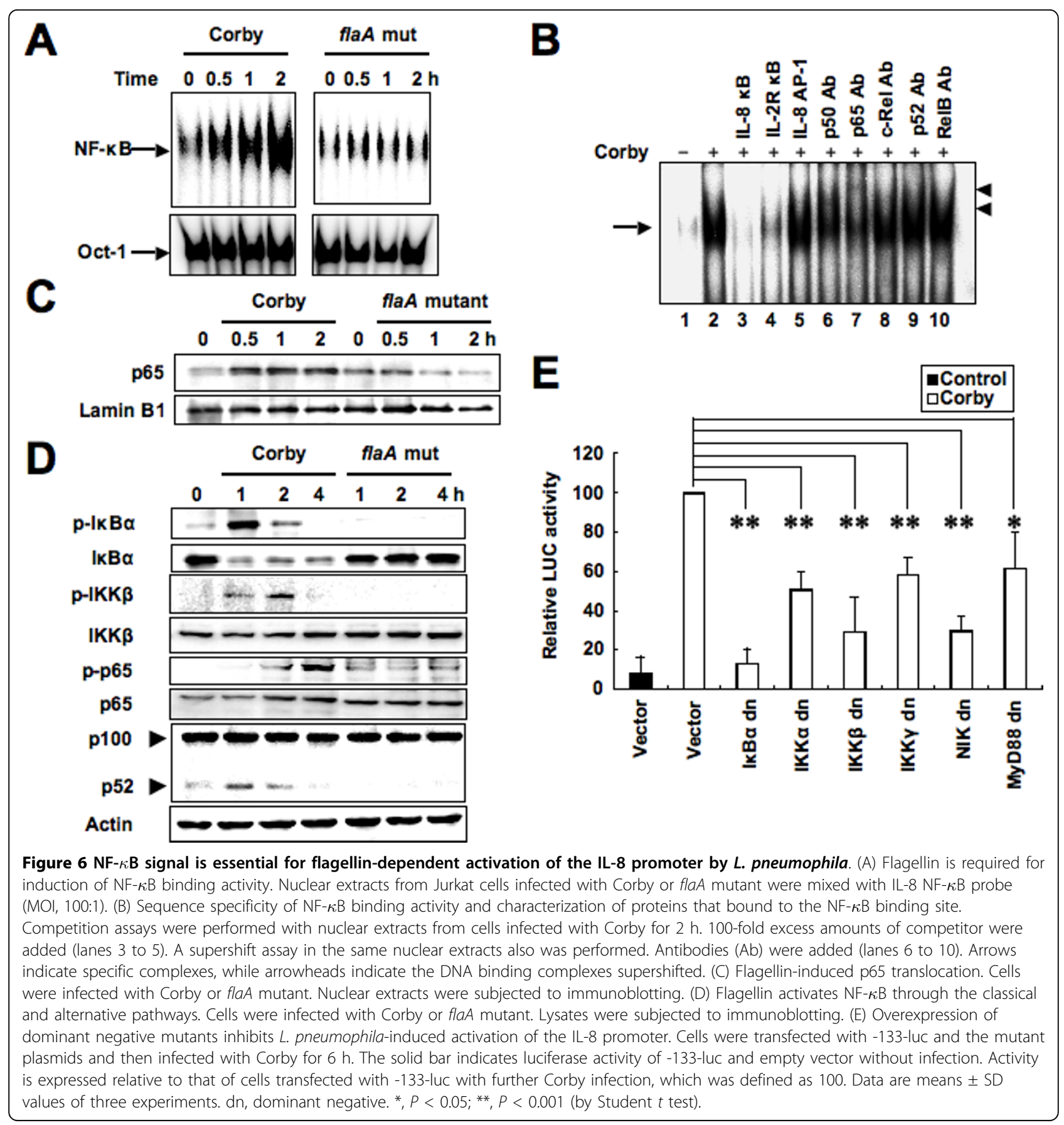

$\mathrm{I} \kappa \mathrm{B} \alpha$ phosphorylation and degradation in L. pneumophila-induced NF- $\kappa \mathrm{B}$ translocation and activation, we investigated whether L. pneumophila induces phosphorylation and degradation of $\mathrm{I} \kappa \mathrm{B} \alpha$. The latter two processes were examined by Western blot analysis using antibodies against phosphorylated and total $\mathrm{I} \kappa \mathrm{B} \alpha$, respectively. Fig. 6D shows phosphorylation and degradation of $\mathrm{I} \kappa \mathrm{B} \alpha$ in Jurkat cells infected with the wildtype Corby but not the flaA mutant for 1,2 and $4 \mathrm{~h}$. The $\mathrm{I} \kappa \mathrm{B} \alpha$ phosphorylation became evident at $1 \mathrm{~h}$ and decreased thereafter. Consistent with this, Corbyinduced degradation of $\mathrm{I} \kappa \mathrm{B} \alpha$ was observed at $1 \mathrm{~h}$.

$\mathrm{NF}-\kappa \mathrm{B}$ signaling occurs either through the classical or alternative pathway [10]. In the classical pathway, NF$\kappa \mathrm{B}$ dimers, such as $\mathrm{p} 50 / \mathrm{p} 65$, are maintained in the cytoplasm by interaction with $\mathrm{I} \kappa \mathrm{B} \alpha$. Whereas the classical NF- $\kappa \mathrm{B}$ activation is $\mathrm{I} \kappa \mathrm{B}$ kinase $\beta(\mathrm{IKK} \beta)$ - and IKK $\gamma$-dependent and occurs through $\mathrm{I} \kappa \mathrm{B} \alpha$ phosphorylation and subsequent proteasomal degradation, the alternative pathway depends on IKK $\alpha$ homodimers and 
NF- $\kappa \mathrm{B}$-inducing kinase (NIK) and results in regulated processing of the $\mathrm{p} 100$ precursor protein to $\mathrm{p} 52$ via phosphorylation and degradation of its $\mathrm{I} \kappa \mathrm{B}$-terminus [10]. Indeed, the wild-type Corby but not the flaA mutant induced phosphorylation of p65 and upstream kinase IKK $\beta$ (Fig. 6D). Next, we examined the alternative pathway, which involves the cleavage of NF- $\kappa \mathrm{B} 2 /$ $\mathrm{p} 100$ to $\mathrm{p} 52$. The level of $\mathrm{p} 52$ protein increased in Jurkat cells infected with the wild-type Corby but not the flaA mutant (Fig. 6D), indicating that flagellin activates NF$\kappa \mathrm{B}$ via the alternative pathway.

\section{$\mathrm{NF}-\kappa \mathrm{B}$ signal is essential for induction of IL-8 expression}

\section{by L. pneumophila}

To further confirm the involvement of $\mathrm{I} \kappa \mathrm{B} \alpha$ degradation, we transfected the cells with transdominant mutant of $\mathrm{I} \kappa \mathrm{B} \alpha$ in which two critical serine residues required for inducer-mediated phosphorylation were deleted [11]. As seen in Fig. 6E, overexpression of mutant $\mathrm{I} \kappa \mathrm{B} \alpha$ greatly inhibited the Corby-induced IL- 8 promoter activation. This observation implicates the involvement of $\mathrm{I} \kappa \mathrm{B} \alpha$ phosphorylation and degradation in flagellininduced IL-8 expression.
To address the mechanism of flagellin-mediated IL-8 expression, we investigated the role of NIK and IKK in L. pneumophila-induced IL-8 expression. Cotransfection with the dominant-negative mutant forms of NIK, IKK $\alpha$, IKK $\beta$, and IKK $\gamma$ inhibited L. pneumophilainduced IL-8 expression (Fig. 6E). MyD88 is a universal adaptor for induction of cytokines by TLR2, TLR4, TLR5, TLR7, and TLR9. It is also required for activation of NF- $\kappa$ B by these TLRs [12]. Likewise, overexpression of a dominant negative mutant form of MyD88 also inhibited L. pneumophila-induced IL-8 expression. Taken together, these findings clearly demonstrate that L. pneumophila induces IL-8 expression via activation of flagellin-dependent NF- $\kappa$ B signaling pathway.

Because activation of the IL-8 promoter by L. pneumophila infection required the activation of NF- $\kappa \mathrm{B}$, we blocked NF- $\kappa$ B activation with Bay 11-7082, an inhibitor of $\mathrm{I} \kappa \mathrm{B} \alpha$ phosphorylation [13]. Bay 11-7082 markedly inhibited $L$. pneumophila-induced phosphorylation and degradation of $\mathrm{I} \kappa \mathrm{B} \alpha$, as well as NF- $\kappa \mathrm{B}$ DNA binding (Fig. 7A and 7B). Furthermore, Bay 11-7082 resulted in a dose-dependent reduction in L. pneumophila-induced

A
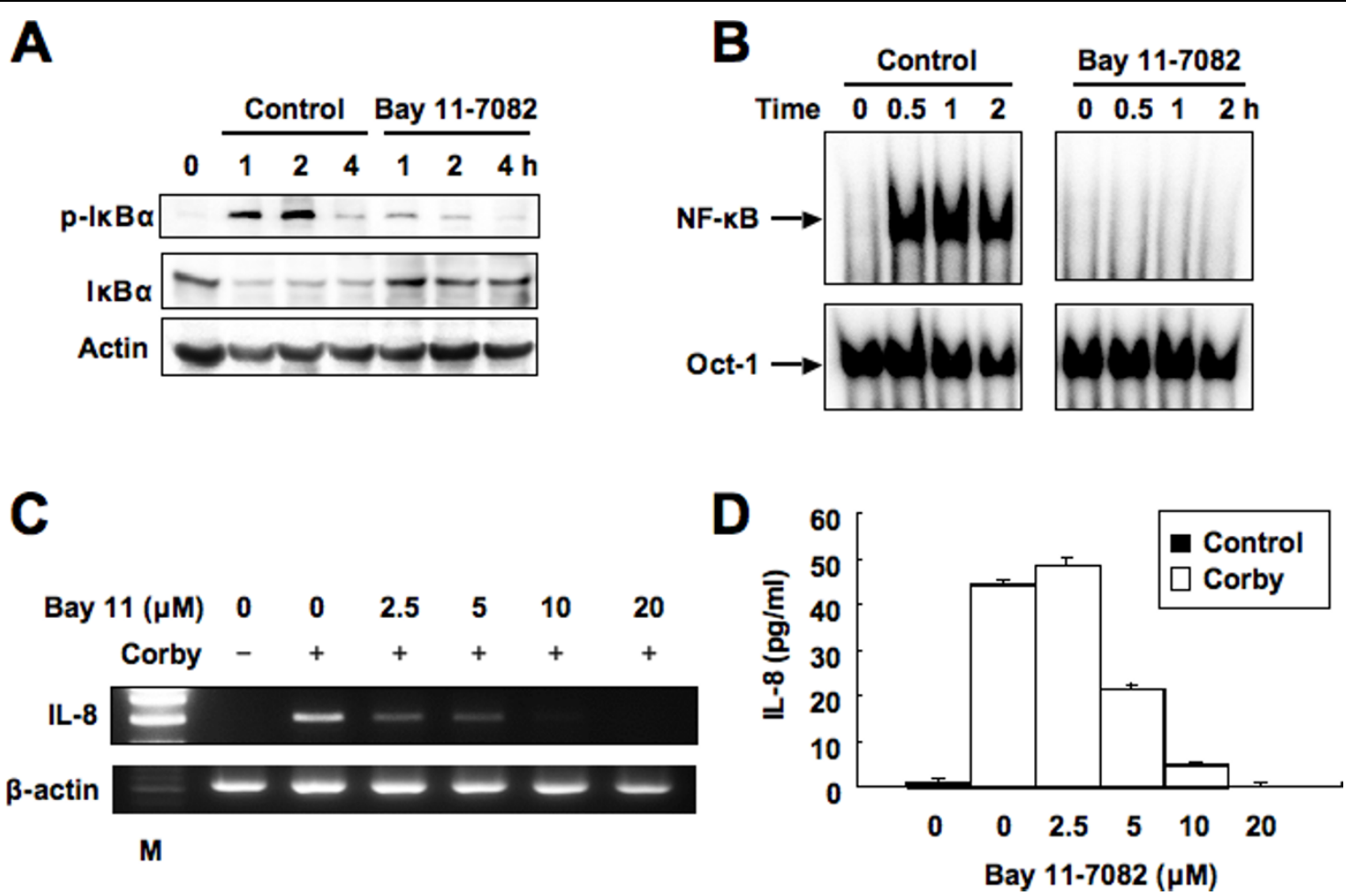

Figure 7 Bay 11-7082 blocks $L$. pneumophila-induced NF- $\kappa$ B activation and IL-8 secretion. Jurkat cells were pretreated with or without Bay 11-7082 (20 $\mu \mathrm{M})$ for $1 \mathrm{~h}$ prior to L. pneumophila Corby infection and subsequently were infected with Corby (MOl, 100:1) for the indicated times. Cell lysates were prepared and subjected to immunoblotting with the indicated antibodies (A) and nuclear extracts from the harvested cells were analyzed for NF- $\kappa$ B and Oct-1 (B). Jurkat cells were pretreated with the indicated concentrations of Bay 11-7082 for $1 \mathrm{~h}$ prior to Corby infection and subsequently infected with Corby (MOI, 100:1) for $4 \mathrm{~h}(\mathrm{C})$ and $24 \mathrm{~h}$ (D). IL-8 mRNA expression on the harvested cells was analyzed by RT-PCR (C) and the supernatants were subjected to ELISA to determine IL-8 secretion (D). Data in (A)-(C) are representative examples of three independent experiments with similar results. Data are mean \pm SD from three experiments. 
IL-8 mRNA expression and secretion by Jurkat cells (Fig. 7C and 7D).

Flagellin-dependent activation of AP-1

To obtain further evidence for the AP-1 site on the IL-8 promoter in response to L. pneumophila, we examined the nuclear factors that bind to this site. The AP-1 sequence derived from the IL-8 promoter was used as a probe in EMSA. Jurkat cells were infected with the wild-type Corby or the flaA mutant at different times after challenge, and nuclear protein extracts were prepared and analyzed to determine AP-1 DNA binding activity. As shown in Fig. 8A, markedly increased complexes were induced by Corby compared with that induced by the isogenic flaA mutant. These results indicate that better activation of AP-1 binding by the flagellin-positive strain is the underlying mechanism of the observed activation of the IL-8 promoter by L. pneumophila. This AP- 1 binding activity to the IL- 8 promoter was reduced by the addition of either cold probe or a CREB sequence but not by an NF- $\kappa$ B sequence derived from the IL-2R $\alpha$ enhancer (Fig. 8B, lanes 2 to 4 ).

Next, we characterized the L. pneumophila-induced complexes identified by the IL- 8 AP- 1 probe. These complexes were diminished and supershifted by the addition of anti-c-Jun, anti-JunD, anti-ATF1, or antiCREB antibody (Fig. 8B, lanes 10, 12, 13, and 17). The addition of these four antibodies completely diminished AP-1 DNA binding (Fig. 8B, lane 19). These results suggest that flagellin-induced IL-8 AP-1 complexes are composed of c-Jun, JunD, ATF1, and CREB to the AP-1 site in the IL-8 promoter region. Next, we examined phosphorylation of these four proteins in Jurkat cells

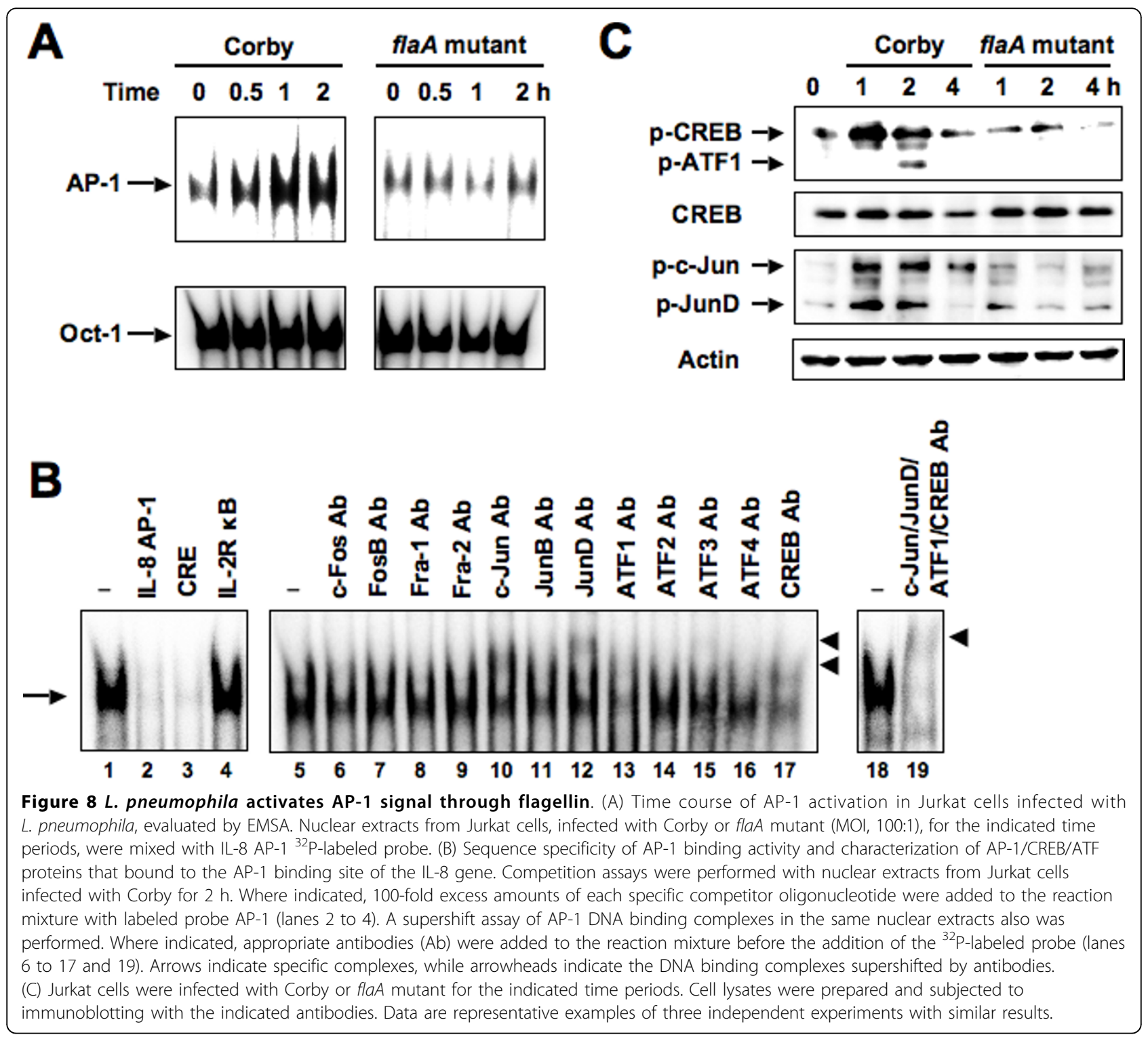


infected with Corby or the isogenic flaA mutant. Corby but not flaA mutant enhanced phosphorylation of c-Jun, JunD, ATF1, and CREB in a time-dependent manner (Fig. 8C). These transcription factors are phosphorylated by p38 MAPK, JNK, and extracellular signal-regulated kinase (ERK) [14-18]. Furthermore, activated MAPKs phosphorylate AP-1, CREB, and ATF complexes, which results in increased AP-1-dependent transcription. We investigated whether L. pneumophila Corby activates these MAPKs.

The p38 MAPK pathway mediates activation of CREB and ATF1 by flagellin

Phosphorylation of p38 MAPK by Corby was determined by Western blot analysis (Fig. 9A). Corby, but not the flaA mutant, phosphorylated MAPKAPK-2 and MSK1, downstream CREB/ATF kinases of p38 MAPK in Jurkat cells (Fig. 9A). Consistent with the role of p38
MAPK phosphorylation in Jurkat cells infected with Corby in IL-8 expression and release, SB203580, a p38 MAPK inhibitor, reduced Corby-induced IL-8 expression and release by Jurkat cells in a dose-dependent manner (Fig. 9B and 9C). Furthermore, SB203580 inhibited Corby-induced luciferase activity of the IL-8 promoter in a dose-dependent manner (Fig. 9D). Similarly, overexpression of a dominant-negative mutant form of either p38 $\alpha$ or p38 $\beta$ also inhibited Corby-induced luciferase activity of the IL- 8 promoter, confirming the involvement of p38 MAPK in flagellin-induced IL-8 expression (Fig. 9E). The finding that SB203580 prevented Corby-induced phosphorylation of CREB and ATF1, and MAPKAPK-2 and MSK1, downstream targets of p38 MAPK (Fig. 9F), suggests that MAPKAPK-2 and MSK1 seem to mediate the flagellin-induced phosphorylation of CREB and ATF1.

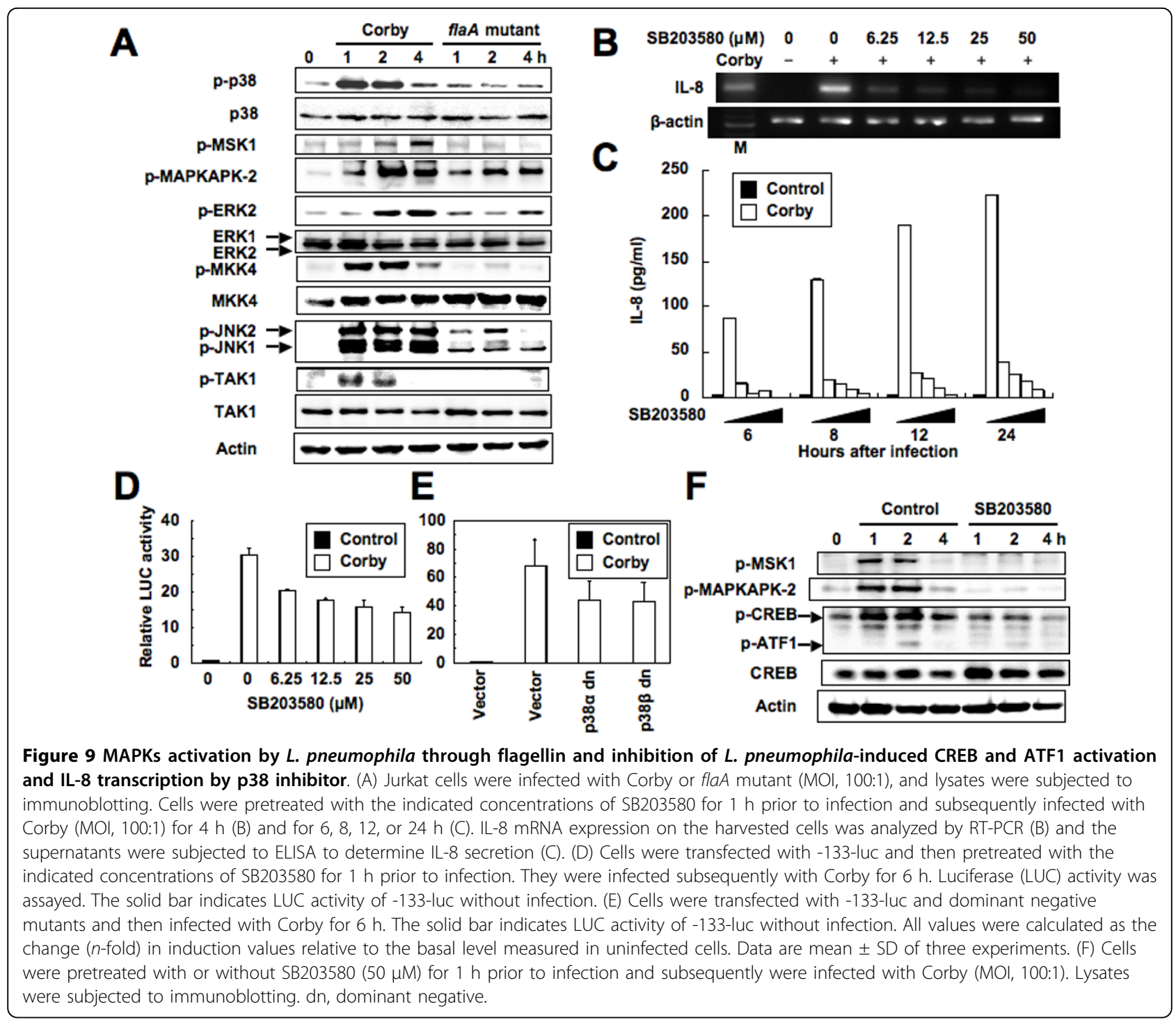




\section{Effects of JNK and ERK on flagellin-induced}

\section{IL-8 expression}

We also examined the effect of flagellin on activation of JNK and ERK. Corby, but not the flaA mutant, markedly increased the phosphorylation of JNK and MAPK kinase 4. (MKK4), upstream activator of JNK, and ERK in Jurkat cells (Fig. 9A). In addition, SP600125, an inhibitor of JNK, suppressed Corby-induced IL-8 expression and release in a dose-dependent manner (Fig. 10A and 10B). The finding that SP600125 inhibited Corby-induced phosphorylation of c-Jun but not JunD (Fig. 10C), suggests that JNK seems to mediate the flagellin-induced phosphorylation of c-Jun.

To determine the direct role of ERK phosphorylation in L. pneumophila-induced IL-8 expression, Jurkat cells were infected with Corby in the absence or presence of PD98059, an inhibitor of MEK1/2, an upstream activator of ERK. RNA and supernatants were collected after 4 and $24 \mathrm{~h}$ of infection and assayed for IL-8 mRNA expression and release, respectively. The addition of PD98059 had no effect on L. pneumophila-induced IL-8 mRNA expression and release by Jurkat cells (Fig. 11A and 11B). The activity of this inhibitor was verified by examining the phosphorylation state of ERK in L. pneumophila-infected cells after selected incubation time periods with PD98059. Whereas ERK activity was reduced in Jurkat cells in the presence of the inhibitor, the phosphorylation of CREB, ATF1, c-Jun, and JunD was not affected (Fig. 11C).

\section{Effect of TAK1 on flagellin-induced IL-8 expression}

TAK1 is one of the most characterized MAPK kinase kinase family members and is activated by various cellular stresses including IL-1 $[19,20]$. TAK1 functions as an upstream stimulatory molecule of the JNK, p38 MAPK, and IKK signaling pathways. Accordingly, we investigated whether TAK1 is also involved in L. pneumophila-induced IL-8 expression. As shown in Fig. 9A, phosphorylation of TAK1 was induced in Jurkat cells infected with Corby but not with flaA mutant. Furthermore, a dominant negative mutant of TAK1 inhibited L. pneumophila-induced IL-8 activation (Fig. 11D). These data suggest that trifurcation of L. pneumophila flagellin-induced IKK-I $\kappa \mathrm{B}, \mathrm{MKK} 4-\mathrm{JNK}$, and p38 MAPK signaling pathways occurs at TAK1.

\section{Discussion}

Innate immunity is essential for limiting L. pneumophila infection at cellular and microbe levels. TLRs are involved in controlling L. pneumophila infection in vivo, since mice lacking TLR2 are more susceptible to infection, and MyD88-deficient mice show defective control of L. pneumophila infection $[21,22]$. Knowledge about

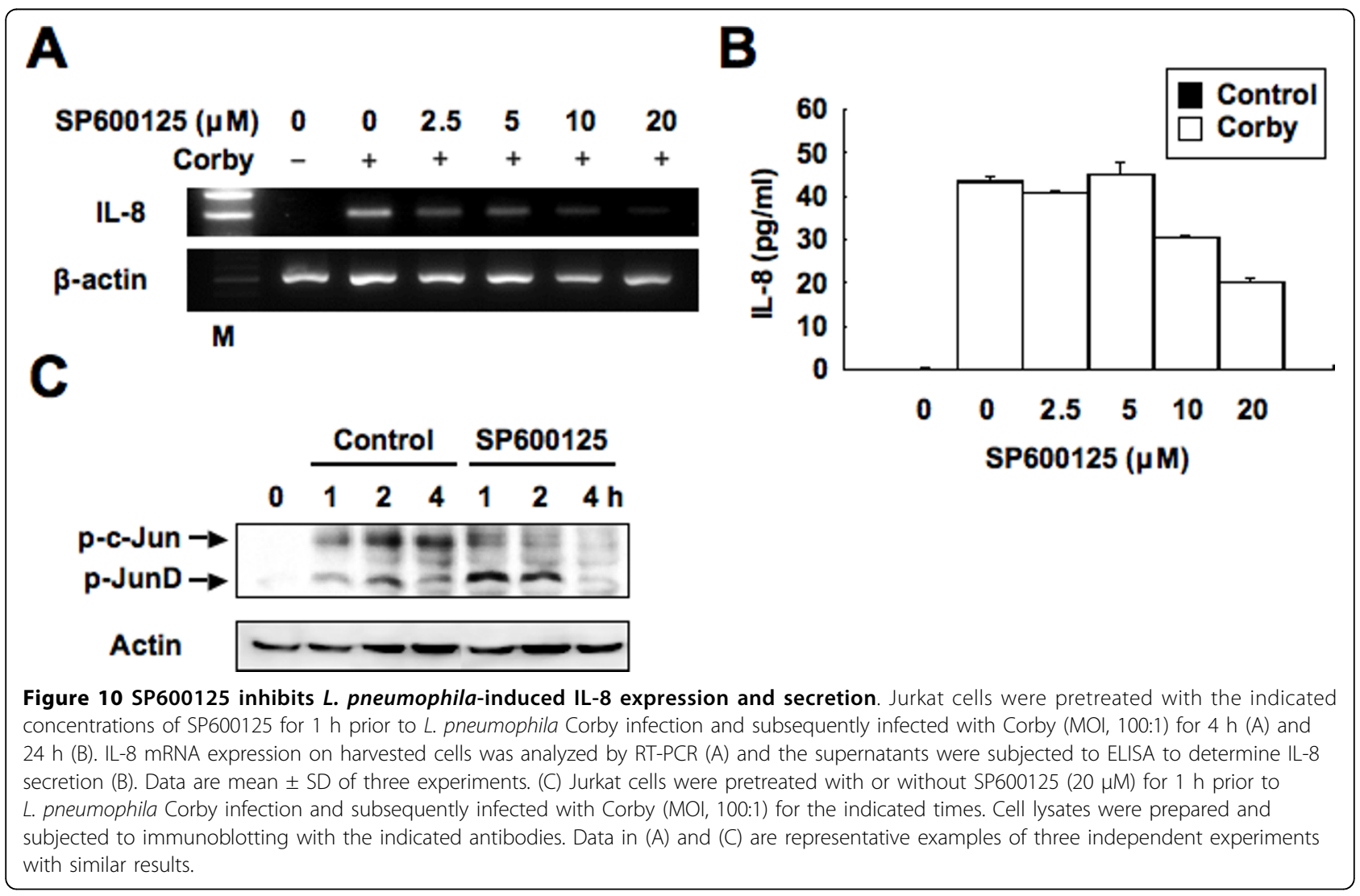




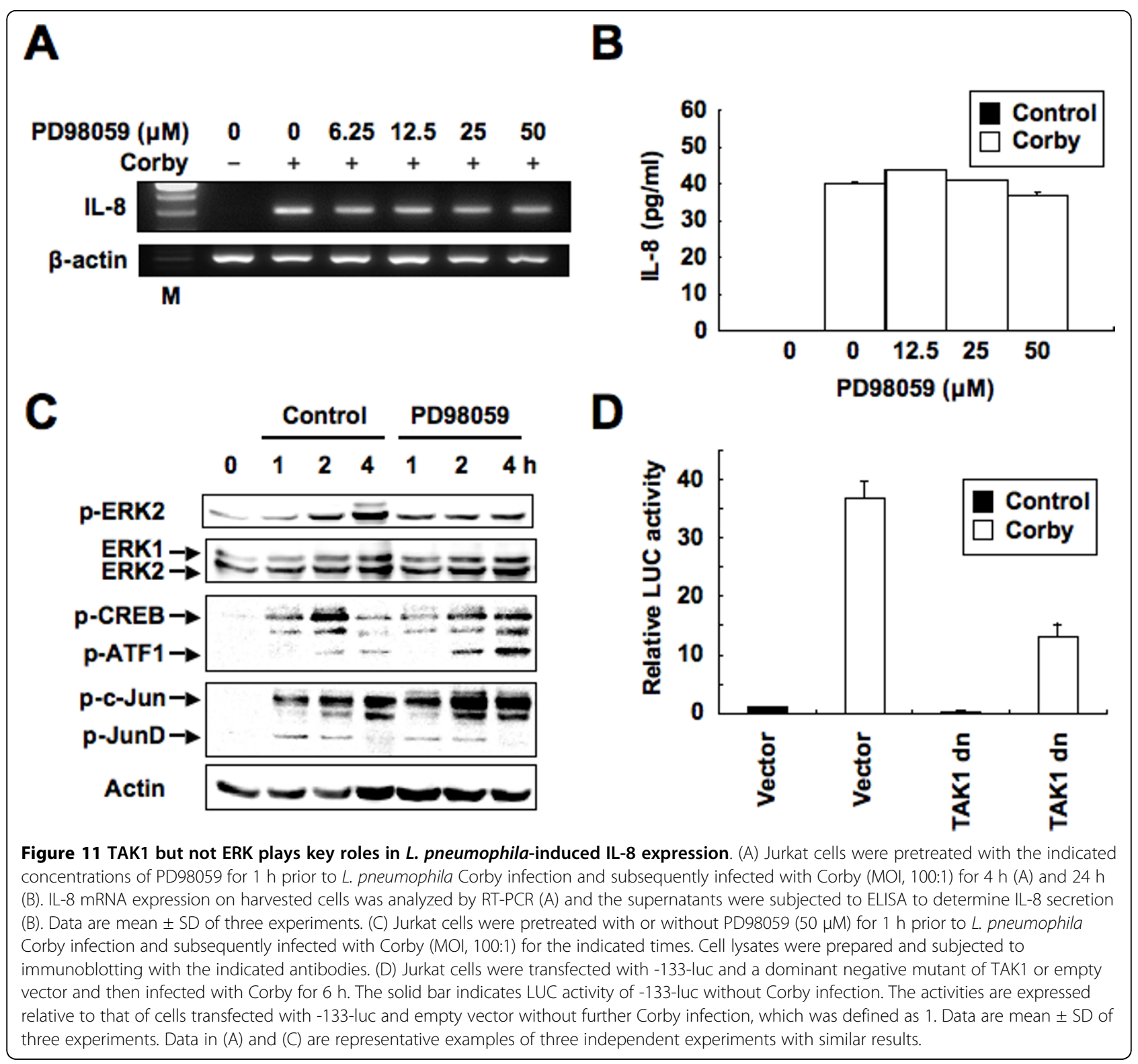

host immunoreaction against L pneumophila is mainly based on studies on macrophages. While adaptive immunity has been shown to be important for host resistance to L. pneumophila [23], the direct interaction of bacteria with adaptive immune cells such as T cells is not well known. In this study, we show that L. pneumophila stimulates Jurkat T cells. Furthermore, this stimulation of $\mathrm{T}$ cells is mainly provided by flagellin since the flaA mutant was deficient in stimulating $\mathrm{T}$ cells to produce IL-8. This difference was independent of bacterial replication, as the flaA mutant could replicate in Jurkat $\mathrm{T}$ cells. Although Legionella less efficiently replicates within $\mathrm{T}$ cells, it is possible that uninfected $\mathrm{T}$ cells might respond to extracellular flagellin. Whether or not $\mathrm{T}$ cells are infected with $L$. pneumophila in vivo, they might still conceivably be a source of IL-8, because extracellular flagellin could induce IL-8 expression [24] and induction of IL-8 by L. pneumophilla did not require invasion. Interestingly, TLR5-deficient mice had lower numbers of polymorphonuclear neutrophils in their broncho-alveolar lavage fluid in comparison to wild-type mice after Legionella infection [25].

Infection with flagellin-deficient $L$. pneumophila has been reported to induce a robust cytokine response equivalent to infection with wild-type $L$. pneumophila in macrophages [26]. This cytokine response requires a functional L. pneumophila Dot/Icm type IV secretion system in macrophages and dendritic cells [26-28], indicating that $\mathrm{T}$ cells are unique. Although bacterial lipoprotein can also stimulate $\mathrm{T}$ cells $[29,30]$, stimulation 
with lipoprotein of L. pneumophila has not yet been shown for human $\mathrm{T}$ cells.

In this study, we demonstrated that L. pneumophila induces IL- 8 expression through flagellin and NF- $\kappa \mathrm{B}$ signaling pathway modulates this induction in human $\mathrm{T}$ cells. Using a specific pharmacological inhibitor, we showed that IKK-NF- $\kappa$ B pathway augmented $L$. pneumophila induction of IL-8 expression. We confirmed the important role of NF- $\kappa$ B by showing that overexpression of dominant negative NIK, IKKs, and $\mathrm{I} \kappa \mathrm{B} \alpha$, potent inhibitors of NF- $\kappa \mathrm{B}$ activation, inhibited IL-8 promoter activation by $L$. pneumophila. The alternative pathway proceeds via NIK-, IKKa, and protein synthesis-dependent processing of the p100 precursor protein to the p52 form and resulted in a delayed but sustained activation of primarily RelB-containing NF- $\kappa \mathrm{B}$ dimmers [10]. The Legionella type IV effector LegK1 has been recently reported to process p100 into p52 [31]. The dominant negative mutants of NIK and IKK $\alpha$ inhibited IL-8 promoter activation by L. pneumophila in Jurkat cells. Furthermore, L. pneumophila infection induced p100 processing into p52 subunit, although supershift experiments did not reveal that the NF- $\kappa$ B-DNA binding complexes in Jurkat cells infected with L. pneumophila involve p52 and RelB. Further basic investigations with knockout and knockdown experiments will be essential in exploring the involvement of NIK-dependent alternative NF- $\kappa$ B pathway in L. pneumophila flagellininduced IL-8 expression in T cells.

Recently, infection with L. pneumophila has been shown to induce a biphasic activation of NF- $\kappa \mathrm{B}$ in human epithelial cells: (i) early in infection, bacterial flagellin induces signaling of TLR5 and a transient translocation of p65 into the nucleus and (ii) at later time points, an unknown factor that depends on bacterial replication and a functional Dot/Icm system induces continuous nuclear localization of p65 and permanent degradation of $\mathrm{I} \kappa \mathrm{B} \alpha$ [32]. Certainly, IL-8 mRNA expression was induced immediately after the infection, but became gradually weaker from 8 to $12 \mathrm{~h}$ after infection with the dotO mutant in Jurkat cells. L. pneumophila could also induce biphasic activation of NF- $\kappa \mathrm{B}$ in T cells. The Dot/ Icm system was demonstrated to be necessary for NF- $\kappa \mathrm{B}$ activation in infections of human macrophages $[33,34]$. Furthermore, the Corby strain was shown to have a severely reduced Dot/Icm-dependent NF- $\kappa$ B activation [32]. Therefore, the flaA mutant derived from Corby strain might be deficient in infecting $\mathrm{T}$ cells to produce IL-8. In addition to flagellin, the Dot/Icm system might also be necessary for NF- $\kappa \mathrm{B}$ activation and subsequent upregulation of IL- 8 gene in infections of T cells.

In addition to NF- $\kappa \mathrm{B}$ activation, MAPKs have also been implicated in the induction of IL- 8 production [35]. The data presented here showing that all three
MAPKs (p38, JNK, and ERK) were consistently activated upon infection with L. pneumophila in T cells, are in agreement with those published by several groups who have also reported L. pneumophila-dependent activation of these MAPKs in macrophages and lung epithelial cells [35-38]. However, p38 and JNK activation is flagellin-independent in macrophages [26]. Legionella deficient in the Dot/Icm system failed to activate p38 and JNK in macrophages [26,38]. In lung epithelial cells, deletion of the Dot/Icm did not alter IL-8 production, whereas lack of flagellin reduced IL-8 release by Legionella, although flagellin- and Dot/Icm-dependency of MAPKs activation was not analyzed [35]. It is likely that L. pneumophila flagellin provides signals to $\mathrm{T}$ cells as in lung epithelial cells since the flaA mutant failed to activate MAPKs in T cells. While it is clear from this report that blockade of p38 with specific inhibitors but not that of ERK, diminishes IL-8 mRNA expression and release in lung epithelial cells [35], the precise molecular mechanism underlying these inhibitions is not clear yet.

We identified both NF- $\kappa \mathrm{B}$ and AP-1 binding sites on the 5' flanking region of the IL-8 promoter required for maximal induction of IL- 8 by $L$. pneumophila. Because we showed that $L$. pneumophila activated all three MAPKs, we also examined whether L. pneumophila triggers MAPKs-mediated IL-8 production via activation of c-Jun, JunD, CREB, and ATF1, which can bind to the AP-1 region in the IL-8 promoter, as well as its cell specificity. By using specific kinase inhibitors, we also demonstrated that IL-8 expression and production in Jurkat cells was sensitive to inhibition of p38 and JNK but not ERK. Consistent with these findings, L. pneumophila stimulated phosphorylation of c-Jun, CREB, and ATF1 was blocked by inhibitors of p38 and JNK but not ERK. Using dominant negative mutant proteins of $\mathrm{p} 38 \alpha$ and $\mathrm{p} 38 \beta$, we showed that $L$. pneumophila induction of IL-8 was also dependent on the p38 pathway. JunD phosphorylation can be mediated through JNK and ERK pathways [17]. Although both of these molecules were activated in response to L. pneumophila, inhibition of JNK and ERK did not reduce phosphorylation of JunD. Further studies are needed to determine the exact kinase responsible for JunD activation.

Overexpression of dominant negative mutants of MyD88 and TAK1 inhibited L. pneumophila-induced IL-8 activation. Although we did not examine the effects of these dominant negative mutants on NF- $\kappa \mathrm{B}$ and MAPKs activation, our results suggest that trifurcation of L. pneumophila-induced IKK-I $\kappa \mathrm{B}, \mathrm{p} 38$, and MKK4JNK signaling pathways occurs at TAK1 (Fig. 12).

\section{Conclusions}

In summary, we showed that L. pneumophila induced IL-8 expression and subsequent production through 


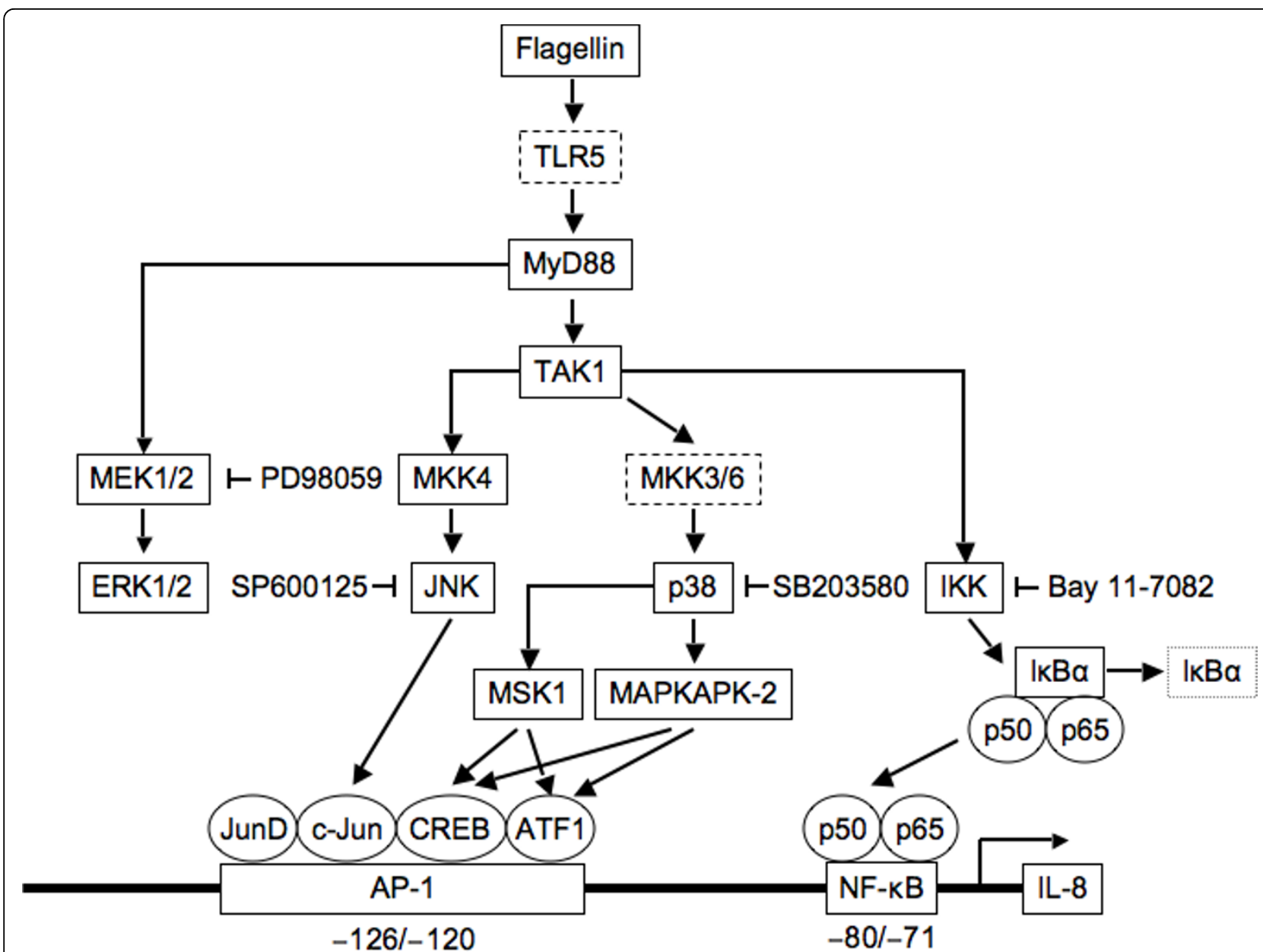

Figure 12 Schematic representation of L. pneumophila-induced signal transduction pathways involved in IL-8 expression human T cells. The contributions of TLR5 and MKK3/6 are deduced.

flagellin in human $\mathrm{T}$ cells. In addition, the study shed new light on the signaling pathways utilized by L. pneumophila in the induction of IL-8. Our findings support the role of IKK-I $\kappa \mathrm{B}, \mathrm{p} 38$, and JNK signaling pathways in L. pneumophila induction of IL-8 in human T cells. Future studies should examine these signaling pathways in T cells of animals and patients infected with $L$. pneumophila, and, if the pathways are found to be significant, a targeted investigation of the role they play in host defense against L. pneumophila in infected animals should be performed.

\section{Methods}

\section{Antibodies and reagents}

Rabbit polyclonal antibodies to $\mathrm{I} \kappa \mathrm{B} \alpha$ and NF- $\kappa \mathrm{B}$ subunits p50, p65, c-Rel, p52, and RelB, AP-1 subunits c-Fos, FosB, Fra-1, Fra-2, c-Jun, JunB, and JunD, ATF/CREB family ATF1, ATF2, ATF3, ATF4, and CREB, mouse monoclonal antibody to $\mathrm{p} 52$, and goat polyclonal antibody to Lamin B were purchased from Santa Cruz
Biotechnology (Santa Cruz, CA). Mouse monoclonal antibody to actin was purchased from NeoMarkers (Fremont, CA). Mouse monoclonal antibody to phospho$\mathrm{I} \kappa \mathrm{B} \alpha$ (Ser-32 and Ser-36), rabbit polyclonal antibodies to p65, IKK $\beta$, p38, phospho-p38 (Thr-180 and Tyr-182), MKK4, phospho-MKK4 (Thr-261), phospho-MAPKAPK-2 (Thr-334), phospho-MSK1 (Ser-360), phosphoJNK (Thr-183 and Tyr-185), phospho-c-Jun (Ser-73), and TAK1, and rabbit monoclonal antibodies to phospho-TAK1 (Thr-184 and Thr-187), phospho-IKKß (Ser180), CREB, phospho-CREB (Ser-133), ERK1/2, and phospho-ERK1/2 (Thr-202 and Tyr-204) were purchased from Cell Signaling Technology (Beverly, MA). Rabbit polyclonal antibody to phospho-p65 (Ser-536) was purchased from Applied Biological Materials (Richmond, Canada). Bay 11-7082 was purchased from Calbiochem (La Jolla, CA), respectively. p38 MAPK inhibitor SB203580, JNK inhibitor SP600125, and MEK1/2 inhibitor PD98059 were obtained from SigmaAldrich (St. Louis, MO). 


\section{Bacterial strains}

L. pneumophila serogroup 1 strain AA100jm [39] is a spontaneous streptomycin-resistant mutant of strain $130 \mathrm{~b}$, which is virulent in guinea pigs, macrophages, and amoebae. The avirulent $\operatorname{dot} O$ mutant was constructed by random transposon mutagenesis, as described previously [39]. This mutation results in severe defects in intracellular growth and evasion of the endocytic pathway [40]. The Corby flaA mutant derived from the wild-type Corby is defective in flagellin [41]. L. pneumophila strains were grown at $35^{\circ} \mathrm{C}$ in a humidified incubator on either buffered charcoal-yeast extract-agar medium supplemented with $\alpha$-ketoglutarate (BCYE- $\alpha$ ) or in buffered yeast extract broth supplemented with $\alpha$-ketoglutarate (BYE$\alpha$ ). The flaA mutant was grown in an environment similar to those used for other strains, but in the presence of $20 \mu \mathrm{g} / \mathrm{ml}$ kanamycin. Heat-killed bacteria were prepared by heating the bacterial suspension at $56^{\circ} \mathrm{C}$ for 30 min or at $100^{\circ} \mathrm{C}$ for $1 \mathrm{~h}$. Bacterial inactivation was achieved by treatment with paraformaldehyde (4\%, 15 min followed by three washes in phosphate-buffered saline; PBS). Both types of treated suspensions were confirmed to contain no viable bacteria by plating them on BCYE- $\alpha$ agar.

\section{Cell culture}

Human T cells (Jurkat) were maintained in RPMI 1640 medium containing $10 \%$ fetal bovine serum (FBS), 100 $\mathrm{U} / \mathrm{ml}$ penicillin $\mathrm{G}$, and $100 \mu \mathrm{g} / \mathrm{ml}$ streptomycin. Human peripheral blood mononuclear cells (PBMC) were isolated from peripheral blood of healthy donors using Ficoll-Hypaque gradients. PBMC were then further purified using positive selection with immunomagnetic beads specific for CD4 (Miltenyi Biotec, Auburn, CA). On the day of the experiment, cells were refed with fresh antibiotic-free medium and cocultured with L. pneumophila for the time intervals indicated below.

\section{Infection of T cells and intracellular growth}

\section{kinetics experiments}

Jurkat or $\mathrm{CD}^{+} \mathrm{T}$ cells seeded in plates were inoculated with either AA100jm or dotO mutant and either Corby or flaA mutant at an MOI of 100. In some experiments, heat-killed or paraformaldehyde-fixed bacteria were inoculated in the same manner. At $2 \mathrm{~h}$ after infection, cells were centrifuged and the supernatant was discarded. Cells were washed three times with PBS and resuspended in fresh RPMI 1640 medium containing $100 \mu \mathrm{g} / \mathrm{ml}$ gentamycin for $2 \mathrm{~h}$. The cells were washed three times again with PBS and were further incubated with fresh medium. The infected cells and supernatant in each well were harvested at the indicated time intervals by washing the wells three times with sterilized distilled water. These bacterial suspensions were diluted in sterilized water and plated in known volume onto BCYE- $\alpha$ agar. The numbers of CFU in infected cells were counted at the indicated time points after infection.

\section{Direct fluorescent antibody staining}

Jurkat cells were infected with bacteria for $2 \mathrm{~h}$, followed by washing three times with PBS and $2 \mathrm{~h}$ gentamycin treatment $(100 \mu \mathrm{g} / \mathrm{ml})$. The infected cells were cultured in fresh antibiotics-free RPMI 1640 medium for an additional $24 \mathrm{~h}$. After being harvested, the cells were fixed in $4 \%$ paraformaldehyde for $15 \mathrm{~min}$. Fixed cells were washed with PBS and permeabilized with PBS containing $0.1 \%$ saponine and $1 \%$ bovine serum albumin for 45 min at room temperature. Permeabilized cells were washed and stained with fluorescein-conjugated mouse anti-L. pneumophila monoclonal antibody (PRO-LAB, Weston, FL) for $45 \mathrm{~min}$ at room temperature. Finally, the cells were washed and observed under a confocal laser scanning microscope (Leica, Wetzlar, Germany). Cells were stained with the nucleic acid dye 4',6-diamidino-2-phenylindole (DAPI).

\section{RT-PCR}

Total cellular RNA was extracted with Trizol (Invitrogen, Carlsbad, CA) according to the protocol provided by the manufacturer. First-strand cDNA was synthesized from 1 $\mu \mathrm{g}$ total cellular RNA using an RNA PCR kit (Takara Bio Inc., Otsu, Japan) with random primers. Thereafter, cDNA was amplified using 30, 35, and 28 cycles for IL-8, TLRs, and for $\beta$-actin, respectively. The specific primers used were as follows: IL-8, forward primer 5'-ATGACTTCCAAGCTGGCCGTG -3' and reverse primer 5'-TTATGAATTCTCAGCCCTCTTCAAAAACTTCTC-3'; TLR2, forward primer 5'-GCCAAAGTCTTGATTGATTGG-3' and reverse primer 5'-TTGAAGTTCTCCAGCTCCTG-3'; TLR3, forward primer 5'-AAGTTGGGCAAGAACTCACAGG-3' and reverse primer 5'-GTGTTTCCAGAGCCGTGCTAA-3'; TLR4, forward primer 5'TGGATACGTTTCCTTATAAG-3' and reverse primer 5'-GAAATGGAGGCACCCCTTC-3'; TLR5, forward primer 5'-CCTCATGACCATCCTCACAGTCAC-3'and reverse primer 5'-GGCTTCAAGGCACCAGCCATCTC3'; and for $\beta$-actin, forward primer 5'-GTGGGGCGCCCCAGGCACCA-3' and reverse primer 5'-CTCCTTAATGTCACGCACGATTTC-3'. The product sizes were $300 \mathrm{bp}$ for IL-8, $347 \mathrm{bp}$ for TLR2, $320 \mathrm{bp}$ for TLR3, $506 \mathrm{bp}$ for TLR4, 355 bp for TLR5, and 548 bp for $\beta$-actin. The thermocycling conditions for the targets were as follows: denaturing at $94^{\circ} \mathrm{C}$ for $30 \mathrm{~s}$ for IL-8, TLR5, and $\beta$-actin, and for $60 \mathrm{~s}$ for TLR3, and $95^{\circ} \mathrm{C}$ for $40 \mathrm{~s}$ for TLR2 and TLR4, annealing at $60^{\circ} \mathrm{C}$ for $30 \mathrm{~s}$ for IL-8 and $\beta$-actin, and for $60 \mathrm{~s}$ for TLR3, and $54^{\circ} \mathrm{C}$ for $40 \mathrm{~s}$ for TLR2 and TLR4, and $55^{\circ} \mathrm{C}$ for $30 \mathrm{~s}$ for TLR5, and extension at $72^{\circ} \mathrm{C}$ for $90 \mathrm{~s}$ for IL- 8 and $\beta$-actin, and for $60 \mathrm{~s}$ for TLR2, TLR3, TLR4, and TLR5. The PCR products were fractionated on $2 \%$ agarose gels and visualized by ethidium bromide staining.

\section{Plasmids}

The $\mathrm{I} \kappa \mathrm{B} \alpha \Delta \mathrm{N}$ dominant negative mutant is $\mathrm{I} \kappa \mathrm{B} \alpha$ deletion mutant lacking the $\mathrm{NH}_{2}$-terminal 36 amino acids 
[11]. The dominant negative mutants of IKK $\alpha$, IKK $\alpha$ (K44M), IKK $\beta$, IKK $\beta$ (K44A), IKK $\gamma$, IKK $\gamma$ (1-305), NIK, NIK (KK429/430AA), MyD88, MyD88 (152-296), and TAK1, TAK1 (K63W), and the dominant negative mutant of either $\mathrm{p} 38 \alpha$ or $\mathrm{p} 38 \beta$, have been described previously $[19,20,42-44]$. Plasmids containing serial deletions of the 5'-flanking region of the IL-8 gene linked to luciferase expression vectors were constructed from a firefly luciferase expression vector [45]. Site-directed mutagenesis of the IL- 8 AP-1, NF-IL-6, and NF- $\kappa$ B sites in the -133-luc plasmid was introduced, converting the AP-1 site TGACTCA (-126 to $-120 \mathrm{bp})$ to TatCTCA, the NF-IL-6 site CAGTTGCAAATCGT (-94 to $-81 \mathrm{bp}$ ) to agcTTGCAAATCGT, and the NF- $\kappa \mathrm{B}$ site GGAATTTCCT (-80 to $-71 \mathrm{bp}$ ) to taAcTTTCCT (lower case letters indicate location of base changes). These constructs were designated as AP-1 site-mutated, NFIL- 6 site-mutated, and NF- $\kappa$ B site-mutated plasmids, respectively.

\section{Transfection and luciferase assay}

Jurkat cells were transfected with $1 \mu \mathrm{g}$ of the appropriate reporter and $4 \mu \mathrm{g}$ of effector plasmids using electroporation. After $24 \mathrm{~h}$, L. pneumophila was infected and incubated for $6 \mathrm{~h}$. The ratio of bacteria to cells (MOI) was 100. The cells were washed in PBS and lysed in reporter lysis buffer (Promega, Madison, WI). Lysates were assayed for reporter gene activity with the dual luciferase assay system (Promega). Luciferase activity was normalized relative to the Renilla luciferase activity from phRL-TK.

\section{Preparation of nuclear extracts and EMSA}

Cell pellets were swirled to a loose suspension and treated with lysis buffer $(0.2 \mathrm{ml}$, containing $10 \mathrm{mM}$ HEPES, $\mathrm{pH}$ 7.9, $10 \mathrm{mM} \mathrm{KCl}, 0.1 \mathrm{mM}$ EDTA, $0.1 \mathrm{mM}$ EGTA, $2 \mathrm{mM}$ AEBSF, and $1 \mathrm{mM}$ DTT) with gentle mixing at $4^{\circ} \mathrm{C}$. After $10 \mathrm{~min}, \mathrm{NP} 40$ was added to a final concentration of $0.6 \%$ and the solution was immediately centrifuged for $5 \mathrm{~min}$ at $1,000 \mathrm{rpm}$ at $4^{\circ} \mathrm{C}$. The supernatants were removed carefully and the nuclear pellets were diluted immediately by the addition of lysis buffer without NP40 (1 ml). The nuclei were then recovered by centrifugation for $5 \mathrm{~min}$ at $1,000 \mathrm{rpm}$ at $4^{\circ} \mathrm{C}$. Finally, the remaining pellets were suspended on ice in the following extraction buffer (20 mM HEPES, $\mathrm{pH} 7.9,0.4 \mathrm{M}$ $\mathrm{NaCl}, 1 \mathrm{mM}$ EDTA, $1 \mathrm{mM}$ EGTA, $1 \mathrm{mM}$ DTT, $2 \mathrm{mM}$ AEBSF, $33 \mu \mathrm{g} / \mathrm{ml}$ aprotinin, $10 \mu \mathrm{g} / \mathrm{ml}$ leupeptin, $10 \mu \mathrm{g} /$ $\mathrm{ml} \mathrm{E}-64$, and $10 \mu \mathrm{g} / \mathrm{ml}$ pepstatin A) for $30 \mathrm{~min}$ to obtain the nuclear fraction. All fractions were cleared by centrifugation for $15 \mathrm{~min}$ at $15,000 \mathrm{rpm}$. NF- $\kappa \mathrm{B}$ and AP-1 binding activities with the NF- $\kappa \mathrm{B}$ and AP-1 elements were examined by EMSA as described previously [46]. To examine the specificity of the NF- $\kappa$ B and AP-1 element probes, we preincubated unlabeled competitor oligonucleotides with nuclear extracts for 15 min before incubation with probes. The probes or competitors used were prepared by annealing the sense and antisense synthetic oligonucleotides as follows: for the NF- $\kappa$ B element of the IL-8 gene, 5'-GATCCGTGGAATTTCCTCTG-3'; for the NF- $\kappa$ B element of the IL-2R $\alpha$ gene, 5'GATCCGGCAGGGGAATCTCCCTCTC-3'; for the AP-1 element of the IL-8 gene, 5'-GATCGTGATGACTCAGGTT-3', and for the consensus sequence of the CRE, 5'- GATCGATCTTTACCATGACGTCAATTTGAT-3'. The oligonucleotide 5'-GATCTGTCGAATGCAAATCACTAGAA-3', containing the consensus sequence of the octamer binding motif, was used to identify specific binding of transcription factor Oct-1. The above bold sequences are the NF- $\kappa \mathrm{B}, \mathrm{AP}-1$, CREB, and Oct-1 binding sites, respectively. To identify NF- $\kappa$ B and AP-1 proteins in the DNA-protein complex shown by EMSA, we used antibodies specific for various NF- $\kappa \mathrm{B}$ family proteins, including $\mathrm{p} 50, \mathrm{p} 65$, c-Rel, p52, and RelB, various AP-1 family proteins, including c-Fos, FosB, Fra-1, Fra-2, c-Jun, JunB, and JunD, and various ATF/CREB family proteins, including ATF1, ATF2, ATF3, ATF4, and CREB, to elicit a supershift DNA-protein complex formation. These antibodies were incubated with the nuclear extracts for $45 \mathrm{~min}$ at room temperature before incubation with radiolabeled probe.

\section{Western blot analysis}

Cells were lysed in a buffer containing $62.5 \mathrm{mM}$ Tris$\mathrm{HCl}(\mathrm{pH} 6.8$ ), $2 \%$ sodium dodecyl sulfate, $10 \%$ glycerol, $6 \% 2$-mercaptoethanol, and $0.01 \%$ bromophenol blue. Equal amounts of protein $(20 \mu \mathrm{g})$ were subjected to electrophoresis on sodium dodecyl sulfate-polyacrylamide gels, followed by transfer to a polyvinylidene difluoride membrane and sequential probing with the specific antibodies. The bands were visualized with an enhanced chemiluminescence kit (Amersham Biosciences, Piscataway, NJ).

\section{Measurement of IL-8}

The IL-8 contents in the serum from peripheral blood and the culture supernatants were measured by ELISA (Biosource International, Camarillo, CA). Serum was obtained from healthy volunteers or each patient with Legionella pneumonia at diagnosis and stored at $-80^{\circ} \mathrm{C}$ until use. Jurkat and $\mathrm{CD} 4^{+} \mathrm{T}$ cells were cultured in RPMI 1640 supplemented with 10\% FBS in 6-well plates. Cells were infected with $L$. pneumophila for the indicated time intervals. The supernatants were then collected after centrifugation and stored at $-80^{\circ} \mathrm{C}$ until assayed for IL- 8 by ELISA. The concentrations of IL- 8 were determined using a standard curve constructed with recombinant IL-8. This study was approved by the Institutional Review Board (IRB) of the University of the Ryukyus with license number H20-12-3. Informed consent was obtained from all blood donors according to the Helsinki Declaration. 


\section{Statistical analysis}

Values were expressed as mean \pm standard deviations (SD). Differences between groups were examined for statistical significance using the Student $t$ test. A $P$ value less than 0.05 was considered statistically significant.

\section{Acknowledgements}

We thank D. W. Ballard for providing the $\mid \kappa B \alpha$ dominant negative mutant; $R$. Geleziunas for providing the NIK, IKK $\alpha$, and IKK $\beta$ dominant negative mutants; K.-T. Jeang for providing the IKK $\gamma$ dominant negative mutant; and M. Muzio for providing the MyD88 dominant negative mutant. This study was supported in part by Grants-in-Aid for Scientific Research (C) 21591211 to N.M. from Japan Society for the Promotion of Science; Scientific Research on Priority Areas 20012044 to N.M. from the Ministry of Education, Culture, Sports, Science and Technology; and the Takeda Science Foundation.

\section{Author details}

${ }^{1}$ Division of Molecular Virology and Oncology, Graduate School of Medicine, University of the Ryukyus, 207 Uehara, Nishihara, Okinawa 903-0215, Japan. ${ }^{2}$ Division of Control and Prevention of Infectious Diseases, Graduate School of Medicine, University of the Ryukyus, 207 Uehara, Nishihara, Okinawa 9030215, Japan. ${ }^{3}$ Transdisciplinary Research Organization for Subtropics and Island Studies, University of the Ryukyus, 1 Senbaru, Nishihara, Okinawa 9030215, Japan. ${ }^{4}$ Department of Molecular Biology, Graduate School of Science, Nagoya University, Chikusa-ku, Nagoya 464-8602, Japan. ${ }^{5}$ Division of Molecular Bioregulation, Cancer Research Institute, Kanazawa University, 13-1 Takara-machi, Kanazawa 920-0934, Japan. ${ }^{6}$ Department of Microbiology and Immunology, University of Rochester Medical Center, 601 Elmwood Avenue, Rochester, New York 14642, USA. ${ }^{7}$ Project group 26 "Nosocomial Infections of the Elderly", Robert Koch-Institut, 20 Nordufer, Berlin 13353, Germany.

\section{Authors' contributions}

RT designed and performed the research, analyzed data, and wrote the manuscript. HT participated in the design of the study, performed the research, and analyzed data. ET and Cl contributed to the experimental concept and provided technical support. $\mathrm{KM}, \mathrm{NMu}$, and JDL carried out the generation of plasmids. $\mathrm{KH}, \mathrm{FH}$, and JF provided bacterial strains. NMo established the research plan, supervised the project, and helped to draft the manuscript. All authors read and approved the data and final version of the manuscript.

\section{Received: 19 July 2009}

Accepted: 5 January 2010 Published: 5 January 2010

\section{References}

1. Joshi AD, Sturgill-Koszycki S, Swanson MS: Evidence that Dot-dependent and -independent factors isolate the Legionella pneumophila phagosome from the endocytic network in mouse macrophages. Cell Microbiol 2001, 3:99-114.

2. Kagan JC, Roy CR: Legionella phagosomes intercept vesicular traffic from endoplasmic reticulum exit sites. Nat Cell Biol 2002, 4:945-954.

3. Molofsky AB, Shetron-Rama LM, Swanson MS: Components of the Legionella pneumophila flagellar regulon contribute to multiple virulence traits, including lysosome avoidance and macrophage death. Infect Immun 2005, 73:5720-5734

4. Neild AL, Roy CR: Immunity to vacuolar pathogens: what can we learn from Legionella? Cell Microbiol 2004, 6:1011-1018.

5. Chang B, Amemura-Maekawa J, Kura F, Kawamura I, Watanabe $\mathrm{H}$ : Expression of IL- 6 and TNF- $\alpha$ in human alveolar epithelial cells is induced by invading, but not by adhering, Legionella pneumophila. Microb Pathog 2004, 37:295-302.

6. Teruya H, Higa F, Akamine M, Ishikawa C, Okudaira T, Tomimori K, Mukaida N, Tateyama M, Heuner K, Fujita J, Mori N: Mechanisms of Legionella pneumophila-induced interleukin-8 expression in human lung epithelial cells. BMC Microbiol 2007, 7:102.

7. Weissgerber $P$, Faigle $M$, Northoff $H$, Neumeister B: Investigation of mechanisms involved in phagocytosis of Legionella pneumophila by human cells. FEMS Microbiol Lett 2003, 219:173-179.
8. Miao EA, Andersen-Nissen E, Warren SE, Aderem A: TLR5 and Ipaf: dual sensors of bacterial flagellin in the innate immune system. Semin Immunopathol 2007, 29:275-288.

9. Hatada EN, Krappmann D, Scheidereit C: NF- $\kappa$ B and the immune response. Curr Opin Immunol 2000, 12:52-58.

10. Dejardin E: The alternative NF- $\kappa$ B pathway from biochemistry to biology: pitfalls and promises for future drug development. Biochem Pharmacol 2006, 72:1161-1179.

11. Brockman JA, Scherer DC, McKinsey TA, Hall SM, Qi X, Lee WY, Ballard DW: Coupling of a signal response domain in $1 \kappa \mathrm{B} \alpha$ to multiple pathways for NF- $\kappa$ B activation. Mol Cell Biol 1995, 15:2809-2818.

12. O'Neill LAJ: The role of MyD88-like adapters in Toll-like receptor signal transduction. Biochem Soc Trans 2003, 31:643-647.

13. Pierce JW, Schoenleber R, Jesmok G, Best J, Moore SA, Collins T, Gerritsen ME: Novel inhibitors of cytokine-induced $I \kappa \mathrm{B} \alpha$ phosphorylation and endothelial cell adhesion molecule expression show anti-inflammatory effects in vivo. J Biol Chem 1997, 272:21096-21103.

14. Davis RJ: Signal transduction by the JNK group of MAP kinases. Cell 2000, 103:239-252

15. Deak $M$, Clifton AD, Lucocq JM, Alessi DR: Mitogen- and stress-activated protein kinase 1 (MSK1) is directly activated by MAPK and SAPK2/p38, and may mediate activation of CREB. EMBO J 1998, 17: 4426-4441.

16. Tan $Y$, Rouse J, Zhang A, Cariati S, Cohen P, Comb MJ: FGF and stress regulate CREB and ATF-1 via a pathway involving p38 MAP kinase and MAPKAP kinase-2. EMBO J 1996, 15:4629-4642.

17. Vinciguerra M, Vivacqua A, Fasanella G, Gallo A, Cuozzo C, Morano A, Maggiolini M, Musti AM: Differential phosphorylation of c-Jun and JunD in response to the epidermal growth factor is determined by the structure of MAPK targeting sequences. J Biol Chem 2004, 279:9634-9641.

18. Zanassi P, Paolillo M, Feliciello A, Avvedimento EV, Gallo V, Schinelli S: cAMPdependent protein kinase induces CAMP-response element-binding protein phosphorylation via an intracellular calcium release/ERKdependent pathway in striatal neurons. J Biol Chem 2001, 276:11487-11495.

19. Ninomiya-Tsuji J, Kishimoto K, Hiyama A, Inoue J-I, Cao Z, Matsumoto K: The kinase TAK 1 can activate the NIK-I $\kappa$ B as well as the MAP kinase cascade in the IL-1 signalling pathway. Nature 1999, 398:252-256.

20. Shuto T, Xu H, Wang B, Han J, Kai H, Gu X-X, Murphy TF, Lim DJ, Li J-D: Activation of NF- $\kappa$ B by nontypeable Hemophilus influenzae is mediated by toll-like receptor 2-TAK1-dependent NIK-IKK $\alpha / \beta-1 \kappa \mathrm{B} \alpha$ and MKK3/6p38 MAP kinase signaling pathways in epithelial cells. Proc Natl Acad Sci USA 2001, 98:8774-8779.

21. Archer KA, Roy CR: MyD88-dependent responses involving toll-like receptor 2 are important for protection and clearance of Legionella pneumophila in a mouse model of Legionnaires' disease. Infect Immun 2006, 74:3325-3333.

22. Hawn TR, Smith KD, Aderem A, Skerrett SJ: Myeloid differentiation primary response gene (88)- and toll-like receptor 2-deficient mice are susceptible to infection with aerosolized Legionella pneumophila. J Infect Dis 2006, 193:1693-1702.

23. Newton C, McHugh S, Widen R, Nakachi N, Klein T, Friedman H: Induction of interleukin-4 (IL-4) by legionella pneumophila infection in BALB/c mice and regulation of tumor necrosis factor alpha, IL-6, and IL-1 $\beta$. Infect Immun 2000, 68:5234-5240.

24. Im J, Jeon JH, Cho MK, Woo SS, Kang S-S, Yun C-H, Lee K, Chung DK, Han $\mathrm{SH}$ : Induction of IL-8 expression by bacterial flagellin is mediated through lipid raft formation and intracellular TLR5 activation in A549 cells. Mol Immunol 2009, 47:614-622.

25. Hawn TR, Berrington WR, Smith IA, Uematsu S, Akira S, Aderem A, Smith KD, Skerrett SJ: Altered inflammatory responses in TLR5-deficient mice infected with Legionella pneumonia. J Immunol 2007, 179:6981-6987.

26. Shin S, Case CL, Archer KA, Nogueira CV, Kobayashi KS, Flavell RA, Roy CR, Zamboni DS: Type IV secretion-dependent activation of host MAP kinases induces an increased proinflammatory cytokine response to Legionella pneumophila. PLOS Pathog 2008, 4:e1000220.

27. McHugh SL, Yamamoto Y, Klein TW, Friedman H: Murine macrophages differentially produce proinflammatory cytokines after infection with virulent vs. avirulent Legionella pneumophila. J Leukoc Biol 2000, 67:863-868.

28. Neild AL, Roy CR: Legionella reveal dendritic cell functions that facilitate selection of antigens for MHC class II presentation. Immunity 2003, 18:813-823. 
29. Liu H, Komai-Koma M, Xu D, Liew FY: Toll-like receptor 2 signaling modulates the functions of $\mathrm{CD}^{+} \mathrm{CD}_{2} 5^{+}$regulatory T cells. Proc Natl Acad Sci USA 2006, 103:7048-7053.

30. Sutmuller RP, den Brok MH, Kramer M, Bennink EJ, Toonen LW, Kullberg B-J, Joosten LA, Akira S, Netea MG, Adema GJ: Toll-like receptor 2 controls expansion and function of regulatory T cells. J Clin Investig 2006, 116: 485-494.

31. Ge J, Xu H, Li T, Zhou Y, Zhang Z, Li S, Liu L, Shao F: A Legionella type IV effector activates the NF- $\kappa \mathrm{B}$ pathway by phosphorylating the $\mathrm{I} \kappa \mathrm{B}$ family of inhibitors. Proc Natl Acad Sci USA 2009, 106:13725-13730.

32. Bartfeld S, Engels $C$, Bauer B, Aurass $P$, Flieger A, Brüggemann $H$, Meyer TF: Temporal resolution of two-tracked NF- $\kappa \mathrm{B}$ activation by Legionella pneumophila. Cell Microbiol 2009, 11:1638-1651.

33. Abu-Zant A, Jones S, Asare R, Suttles J, Price C, Graham J, Kwaik YA: Antiapoptotic signalling by the Dot/lcm secretion system of $L$. pneumophila. Cell Microbiol 2007, 9:246-264.

34. Losick VP, Isberg RR: NF- $\kappa$ B translocation prevents host cell death after low-dose challenge by Legionella pneumophila. J Exp Med 2006, 203:21772189

35. Schmeck B, N'Guessan PD, Ollomang M, Lorenz J, Zahlten J, Opitz B, Flieger A, Suttorp N, Hippenstiel S: Legionella pneumophila-induced NF- $\kappa$ B-and MAPK-dependent cytokine release by lung epithelial cells. Eur Respir J 2007, 29:25-33.

36. Matsunaga $\mathrm{K}$, Yamaguchi $\mathrm{H}$, Klein TW, Friedman $H$, Yamamoto $\mathrm{Y}$ : Legionella pneumophila suppresses macrophage interleukin-12 production by activating the p42/44 mitogen-activated protein kinase cascade. Infect Immun 2003, 71:6672-6675.

37. N'Guessan PD, Etouem MO, Schmeck B, Hocke AC, Scharf S, Vardarova K, Opitz B, Flieger A, Suttorp N, Hippenstiel S: Legionella pneumophila-induced PKC $\alpha$-MAPK-, and NF- $\kappa$ B-dependent COX-2 expression in human lung epithelium. Am J Physiol Lung Cell Mol Physiol 2007, 292:L267-L277.

38. Welsh CT, Summersgill JT, Miller RD: Increases in c-Jun N-terminal kinase/ stress-activated protein kinase and p38 activity in monocyte-derived macrophages following the uptake of Legionella pneumophila. Infect Immun 2004, 72:1512-1518.

39. Edelstein PH, Edelstein MA, Higa F, Falkow S: Discovery of virulence genes of Legionella pneumophila by using signature tagged mutagenesis in a guinea pig pneumonia model. Proc Natl Acad Sci USA 1999, 96:8190-8195.

40. Andrews HL, Vogel JP, Isberg RR: Identification of linked Legionella pneumophila genes essential for intracellular growth and evasion of the endocytic pathway. Infect Immun 1998, 66:950-958.

41. Dietrich C, Heuner K, Brand BC, Hacker J, Steinert M: Flagellum of Legionella pneumophila positively affects the early phase of infection of eukaryotic host cells. Infect Immun 2001, 69:2116-2122.

42. Geleziunas R, Ferrell S, Lin X, Mu Y, Cunningham ETJr, Grant M, Connelly MA, Hambor JE, Marcu KB, Greene WC: Human T-cell leukemia virus type 1 Tax induction of NF- $\kappa \mathrm{B}$ involves activation of the $\mathrm{I} \kappa \mathrm{B}$ kinase $\alpha(\mathrm{IKK} \alpha)$ and IKK $\beta$ cellular kinases. Mol Cell Biol 1998, 18:5157-5165.

43. Iha H, Kibler KV, Yedavalli VRK, Peloponese JM, Haller K, Miyazato A, Kasai T, Jeang K-T: Segregation of NF- $\kappa$ B activation through NEMO/IKK $\gamma$ by Tax and TNF $\alpha$ : implications for stimulus-specific interruption of oncogenic signaling. Oncogene 2003, 22:8912-8923.

44. Muzio M, Ni J, Feng P, Dixit VM: IRAK (Pelle) family member IRAK-2 and MyD88 as proximal mediators of IL-1 signaling. Science 1997, 278:16121615.

45. Okamoto S, Mukaida N, Yasumoto K, Rice N, Ishikawa Y, Horiguchi H, Murakami S, Matsushima K: The interleukin-8 AP-1 and $\kappa$ B-like sites are genetic end targets of FK506-sensitive pathway accompanied by calcium mobilization. J Biol Chem 1994, 269:8582-8589.

46. Mori N, Fujii M, Ikeda S, Yamada Y, Tomonaga M, Ballard DW, Yamamoto N Constitutive activation of NF- $\kappa \mathrm{B}$ in primary adult T-cell leukemia cells. Blood 1999, 93:2360-2368.

doi:10.1186/1471-2180-10-1

Cite this article as: Takamatsu et al:: Molecular characterization of Legionella pneumophila-induced interleukin-8

expression in T cells. BMC Microbiology 2010 10:1.

\section{Submit your next manuscript to BioMed Central and take full advantage of:}

- Convenient online submission

- Thorough peer review

- No space constraints or color figure charges

- Immediate publication on acceptance

- Inclusion in PubMed, CAS, Scopus and Google Scholar

- Research which is freely available for redistribution 